\title{
Impact of Large-Scale Dynamic versus Thermodynamic Climate Conditions on Contrasting Tropical Cyclone Genesis Frequency ${ }^{\circ}$
}

\author{
S. SHARMILA AND K. J. E. WALSH \\ School of Earth Sciences, University of Melbourne, Melbourne, Victoria, Australia
}

(Manuscript received 20 December 2016, in final form 27 July 2017)

\begin{abstract}
Significant advances have been made in understanding the key climate factors responsible for tropical cyclone (TC) activity, yet any theory that estimates likelihood of observed TC formation rates from mean climate states remains elusive. The present study investigates how the extremes of observed TC genesis (TCG) frequency during peak TC seasons are interrelated with distinct changes in the large-scale climate conditions over different ocean basins using the global International Best Track Archive for Climate Stewardship (IBTrACS) dataset and ERA-Interim for the period 1979-2014. Peak TC seasons with significantly high and low TCG frequency are identified for five major ocean basins, and their substantial spatial changes in TCG are noted with regionally distinct differences. To explore the possible climate link behind such changes, a suite of potentially relevant dynamic and thermodynamic climate conditions is analyzed. Results indicate that the observed changes in extreme TCG frequency are closely linked with distinct dominance of specific dynamic and thermodynamic climate conditions over different regions. While the combined influences of dynamic and thermodynamic climate conditions are found to be necessary for modulating TC formation rate over the North Atlantic, eastern Pacific, and southern Indian Oceans, significant changes in large-scale dynamic conditions appear to solely control the TCG frequency over the western Pacific and South Pacific basins. Estimation of the fractional changes in genesis-weighted climate conditions also indicates the coherent but distinct competing effects of different climate conditions on TCG frequency. The present study further points out the need for revising the existing genesis indices for estimating TCG frequency over individual basins.
\end{abstract}

\section{Introduction}

Understanding and modeling the fundamental link between large-scale climate and the statistical distribution of tropical cyclone (TC) activity (e.g., genesis, development, intensity, and frequency) is important both for scientific and socioeconomic reasons (Knutson et al. 2010; Peduzzi et al. 2012). This is partly because TCs form and develop only under certain restricted dynamic and thermodynamic climatic conditions (Gray 1968; McBride and Zehr 1981), and therefore any variation of these conditions leads to substantial TC modulation. Since the pioneering work of Gray (1968), various empirical ideas and techniques have been proposed to

Supplemental information related to this paper is available at the Journals Online website: https://doi.org/10.1175/ JCLI-D-16-0900.s1.

Corresponding author: S. Sharmila, sharmila.sur@unimelb.edu. au

DOI: 10.1175/JCLI-D-16-0900.1

(C) 2017 American Meteorological Society. For information regarding reuse of this content and general copyright information, consult the AMS Copyright Policy (www.ametsoc.org/PUBSReuseLicenses). provide insights into the relationship between climate and TC activity (e.g., Gray 1984; Holland 1997; Landsea et al. 1999; Emanuel and Nolan 2004; Camargo et al. 2007; Emanuel 2010; Tippett et al. 2011; Bruyère et al. 2012). Although significant advances have been made in identifying the key climate factors responsible for TC genesis (TCG) and development, there is little theoretical guidance that quantitatively establishes the likelihood of TCG frequency given specific large-scale climate conditions (Camargo and Hsiang 2015; Walsh et al. 2016).

Statistics show that every year about 80-90 TCs form worldwide (Gray 1979; Frank and Young 2007), while TC records from various basins indicate large interannual changes in TCG frequency with notable regional differences (e.g., Gray 1984; Chia and Ropelewski 2002; Camargo and Sobel 2005; Chen et al. 2006; Vincent et al. 2011; Zhang and Wang 2015). Such large high-low variations in TCG frequency over different ocean basins could be driven in part by differing changes in the largescale climate conditions. However, our knowledge is still 
limited regarding how precisely the large-scale dynamic and thermodynamic climate conditions determine the basinwise statistical extremes of TCG frequency during "peak" (or "active") TC seasons (defined as the season with maximum TCG in each basin), in particular the differing relationships between basins. The present study aims to investigate this crucial issue, with a focus on documenting the competing influences of thermodynamic versus dynamic climate conditions on the basinwise TCG frequency extremes.

Several studies have been devoted to identifying the dominant climatic determinants and the physical mechanisms involved in regulating TC activity, yet our understanding on linking TCG frequency and climate remain incomplete. Gray $(1968,1979)$ first established a benchmark that relates the climatological-seasonal frequency of TCG to a suite of necessary (but not sufficient) large-scale environmental conditions. These were grouped into thermodynamic [sea surface temperature (SST), conditional instability, and midlevel relative humidity] and dynamic (Coriolis parameter, vertical wind shear, and relative vorticity at lower level) conditions. These conditions are not completely independent of each other, however (Frank 1987). While the necessary thermodynamic conditions for TCG, such as $\mathrm{SST}>26.5^{\circ} \mathrm{C}$ (McBride and Zehr 1981), generally exist over the tropical oceans for long periods of time, dynamic conditions can change drastically on much shorter space-time scales, thus regulating the TCG processes (Holland 1995; Briegel and Frank 1997). Consequently, many studies have stressed how largescale dynamic factors could play decisive roles in controlling TCG in different basins (e.g., Lander 1994; Holland 1995; Chen et al. 1998; Ritchie and Holland 1999; Wang and Zhou 2008; Peng et al. 2012). Within the monsoonal environment, dynamic conditions such as low-level relative vorticity largely determine TCG locations (e.g., Gray 1968; Frank 1987; Ritchie and Holland 1999; Chen et al. 2006; Feng et al. 2014; Cao et al. 2014), while in the absence of a monsoon trough, wind shear dictates the most favorable conditions over the North Atlantic and the eastern North Pacific (Camargo et al. 2007). The strength and position of subtropical highs can also help in determining the TCG locations in some basins (Chen et al. 1998; Hsu et al. 2014). A recent decrease in TC activity over the western North Pacific has been detected, induced by changing dynamic conditions, despite enhanced thermodynamically favorable conditions (Liu and Chan 2013).

The interannual variability of TCG is largely induced by various modes of climate variability through modulation of large-scale climate conditions (e.g., Gray 1984;
Maloney and Hartmann 2000; Camargo et al. 2007; Klotzbach 2014). The El Niño-Southern Oscillation (ENSO) phenomenon plays the leading role in driving interannual variability of TCG over several tropical basins with regionally varying impact (Camargo et al. 2010). While change in SSTs is the main thermodynamic contributor (Gray 1984), wind shear is the main ENSOinduced dynamic factor (Wang and Lee 2009). Over the western Pacific, while strong ENSO-induced large-scale climate conditions increase TC activity (e.g., Chan 1985; Chen et al. 1998; Kim et al. 2011; Zhao et al. 2016), the annual TC number appears almost uncorrelated with ENSO indices (Lander 1994; Wang and Chan 2002; Liu and Chan 2013). In the eastern North Pacific, the number of intense TCs is found to be modulated by ENSOinduced wind shear (Frank and Young 2007), while the potential intensity (a parameter based on thermodynamics; Emanuel 1988) plays a secondary role (Camargo et al. 2007). However, the overall basinwide number of TCs does not appear to be significantly altered by ENSO (Whitney and Hobgood 1997). Over the North Atlantic, the ENSO-induced dynamic effect was also found to be more important than the thermodynamic effect (Goldenberg et al. 2001; Camargo et al. 2007; Klotzbach 2011). Nevertheless, some studies argued for the dominance of ambient thermodynamic influences (such as midlevel dryness and increased moist stability) in the suppression of TC activity (Tang and Neelin 2004; Patricola et al. 2014). In the south Indian region, while an increase in TCs and a westward shift in TCG locations were noted during El Niño events (Kuleshov et al. 2008), other studies attributed such variations to the opposing effects of upper-level westerlies and enhanced convection (Jury 1993). In the South Pacific and Australian basins, the TC activity shows varied response to ENSO-induced climate conditions, such as notable spatial displacement of mean TCG during ENSO (e.g., Nicholls 1984; Basher and Zheng 1995; Frank and Young 2007; Kuleshov et al. 2009; Dowdy et al. 2012; Ramsay et al. 2012). However, the total number of TCs shows only a weak relationship (Nicholls et al.1998). Note that differences in timing and evolution of individual ENSOs events with respect to the peak TC seasons could also complicate their role in changing the seasonal TCG frequency (Chia and Ropelewski 2002).

Based on Gray's (1968) general theoretical approach, many studies later refined the ingredients and developed different empirical indices as proxies for assessing TCG (Gray 1979; Holland 1997; Camargo et al. 2007; Tippett et al. 2011; Emanuel and Nolan 2004). These indices show reasonable skill in depicting the annual cycle of TC activity and have potential to reveal the relative 
importance of various large-scale climate factors during ENSO events (Camargo et al. 2007). However, their limited skill in capturing basinwise estimates of TCG frequency has made individual contributions of largescale climate factors rather speculative (Menkes et al. 2012; Bruyère et al. 2012). This constraint could perhaps be due to the limited understanding of each of the individual factors and their differing relationships between basins. Recent studies also support the idea that the large-scale dynamic and thermodynamic climate conditions do not impact the TCG in the same way over all basins during peak TC seasons (Gualdi et al. 2007; Nolan and Rappin 2008).

All these issues necessitate a systematic framework that could determine the individual contributions of dynamic and thermodynamic climate conditions, their differing relationships between basins, and their competing impacts on regional differences in TCG frequency during peak TC seasons. Using updated observations and recent reanalyses, the present study therefore provides a comprehensive analysis on how the basinwise statistically extreme observed TCG frequency during active TC seasons could be closely related to distinct changes in large-scale climate conditions over different ocean basins. This study further uses a genesisweighted quantitative analysis approach (Held and Zhao 2011) to reveal the competing effects of dynamic and thermodynamic conditions.

The rest of the paper is structured as follows: Section 2 outlines the various datasets and analysis methods used in this study. Sections 3 and 4 provide a statistical evaluation of the relationship between observed TCG frequency and changes in large-scale climate conditions. The summary and conclusions are discussed in section 5 .

\section{Data and method}

\section{a. Observational and reanalysis data}

We use the 6-hourly TC best-track data from the WMO International Best Track Archive for Climate Stewardship (IBTrACS) project (v03r08; Knapp et al. 2010; https://www.ncdc.noaa.gov/ibtracs). This dataset represents the most complete collection of global TC datasets. To ensure data reliability and a more accurate climatology, data for the most recent 36 years (19792014) are used.

Most of the climate variables analyzed here are extracted from monthly data of ERA-Interim (Dee et al. 2011; http://apps.ecmwf.int/datasets/data/interim-fullmoda/) of resolution $1.5^{\circ} \times 1.5^{\circ}$ for the same 36 -yr period. We also use monthly Extended Reconstructed SST (ERSSTv4; Huang et al. 2014) of resolution $2^{\circ} \times 2^{\circ}$ provided by NOAA (http://www.ersl.noaa.gov/psd/) for comparison (not shown).

\section{b. Domain and definition of TCG}

The TC best-track dataset is grouped into five TC active ocean basins, namely, western Pacific (WP), eastern Pacific (EP), North Atlantic (NA), south Indian Ocean (SI), and South Pacific (SP) (Fig. 1). We have excluded the north Indian Ocean basin because TCs are infrequently labeled before 1990 in this best-track version. Here, only the TCs that form within the tropical domain of $30^{\circ} \mathrm{S}-30^{\circ} \mathrm{N}$ are considered for this study. The number of TCG is defined as the number of tropical storms that exceed maximum wind of $33 \mathrm{kt}\left(\approx 17 \mathrm{~m} \mathrm{~s}^{-1}\right)$. The location of TCG is identified based on the position of the tropical storms at which the maximum wind speed exceeds $33 \mathrm{kt}$, and the TCG distribution is computed for each $2^{\circ} \times 2^{\circ}$ grid box. Based on the $36 \mathrm{yr}$ of TC best-track data, the annual number of TCG over five ocean basins is identified (Table 1, top). Among all basins, the WP is the most active region of TCG and experiences about one-third of all TCs that form across the globe, while the TC interannual coefficient of variation is highest (above $40 \%$ ) over the NA. The most active months of TCG also vary from one basin to another. Peak TC seasons of each basin with maximum TCG are identified based on previous work. For example, peak TC activity typically occurs during July-October (JASO) in the WP, July-September (JAS) in the EP, August-October (ASO) for the NA, and January-March (JFM) for both the SI and SP. Nearly $70 \%$ of the annual TCs form during the peak TC season in almost all basins (Table 1, bottom). Therefore, any notable change (decrease or increase) in TCG frequency during the peak season will significantly contribute to total TC variability at the interannual time scale.

\section{c. Selection criteria for TCG frequency extremes}

To identify the most contrasting (high and low) peak seasons of TCG frequency extremes, an index is constructed based on TCG number identified per peak season per year. For each ocean basin, the standardized TCG number is obtained by calculating deviations from the long-term mean and then normalizing by their own standard deviations. A peak season of a particular ocean basin is defined as a high TCG season (HTCG) when the index value is $\geq+1.0$ or as a low TCG season (LTCG) when the index value is $\leq-1.0$. Based on the above criterion, all HTCG and LTCG seasons are identified and listed in Table 2.

\section{d. Computation of large-scale climate conditions}

Various large-scale climate conditions are computed here, such as vertical wind shear (VWS), relative 


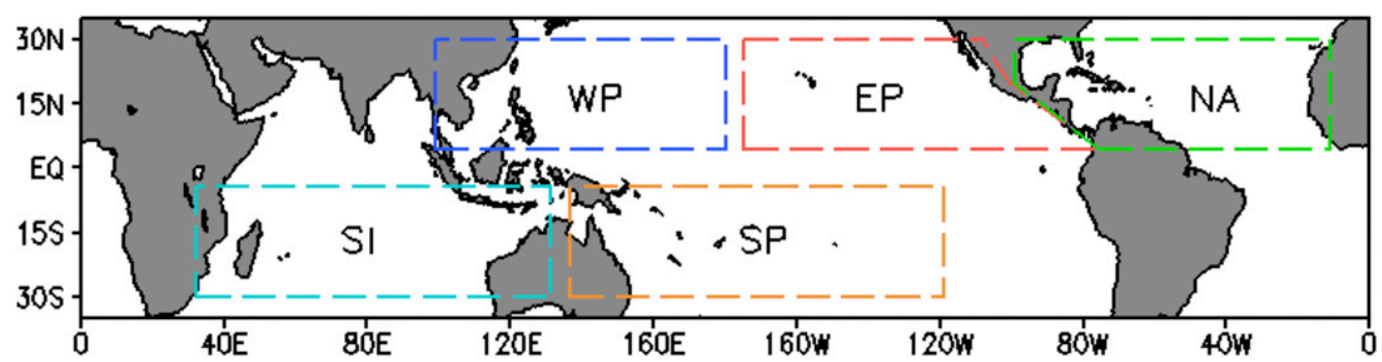

FIG. 1. Global map of ocean basins selected for this study: WP, EP, NA, SI, and SP. No land points were considered in the above domains.

vorticity (RVor), low-level rotational winds (Rwind), maximum potential intensity (MPI), and moisture flux convergence (MFC). VWS is defined as the magnitude of the vector difference of winds between 200 and $850 \mathrm{hPa}$ :

$$
\mathrm{VWS}=\sqrt{\left(u_{200}-u_{850}\right)^{2}+\left(v_{200}-v_{850}\right)^{2}}
$$

$\mathrm{RV}$ or at $850 \mathrm{hPa}$ is computed using a centered finite differencing scheme, while streamfunction $\psi$ is calculated to determine the low-level Rwind at $850 \mathrm{hPa}$, where

$$
u=-\frac{\partial \psi}{\partial y} \quad \text { and } \quad v=+\frac{\partial \psi}{\partial x}
$$

MPI (Emanuel 1988; Holland 1997) is the theoretical maximum intensity that TCs could reach under specific environmental conditions and is often considered relevant to quantify TC activity. Here the MPI is calculated based on Emanuel (1988) and Bister and Emanuel (1998):

$$
\mathrm{MPI}=\frac{T_{s}}{T_{o}} \frac{C_{k}}{C_{D}}\left(\mathrm{CAPE}_{e}-\mathrm{CAPE}_{b}\right),
$$

where $T_{s}$ is the SST, $T_{o}$ is the mean outflow temperature, $C_{k}$ is the exchange coefficient for enthalpy, and $C_{D}$ the drag coefficient. The quantity $\mathrm{CAPE}_{e}$ is the convective available potential energy with reference to the environmental sounding, and $\mathrm{CAPE}_{b}$ is that of boundary layer air.

The vertically integrated (surface- $700 \mathrm{hPa}$ ) low-level MFC is calculated based on Seager et al. (2010):

$$
\mathrm{MFC} \equiv-\frac{1}{\rho_{w} g} \int_{700}^{\mathrm{sfc}} \nabla \cdot \mathbf{V} q d P
$$

where $\rho_{w}$ is the density of water, $g$ is the gravitational constant, $\mathbf{V}$ is the wind vector, $q$ is the specific humidity, and $P$ is pressure.

To highlight the contrasting differences in large-scale variables during HTCG and LTCG seasons, seasonal anomalies of patterns are calculated by subtracting the long-term seasonal climatology (CLIM; 1979-2014). The spatial difference between HTCG and LTCG seasons is also calculated separately. The significance of the results is evaluated using the Student's $t$ test.

\section{Observed changes in TCG frequency}

\section{a. Distribution of TCG frequency}

Figure 2 shows the normalized time series of TCG frequency per peak season for individual ocean basins for the period 1979-2014. Robust interannual variations in TCG frequency are noted in all basins. Based on the criteria listed in section 2c, the extreme HTCG (LTCG) seasons are shown in blue (red) bars, relative to normal seasons (black bars). To identify their association with ENSO, we mark the concurrent El Niño (La Niña) episodes (based on a threshold of above or below \pm 0.5 for the oceanic Niño index) with red (blue) circles for HTCG-LTCG seasons (listed in Table 2).

HTCG and LTCG seasons over some of the basins show notable association with different ENSO phases,

TABLE 1. Statistics of observed TCG frequency for 1979-2014, including (top) long-term average annual TCG number and (bottom) average TCG frequency during peak seasons.

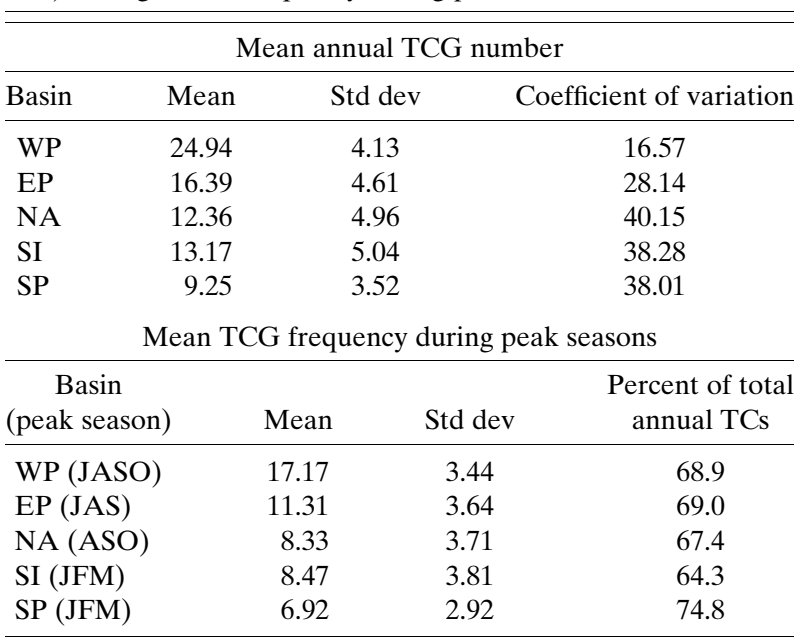


TABLE 2. List of HTCG and LTCG seasons of individual ocean basins considered in this study (source: http://www.cpc.ncep.noaa.gov/ products/analysis_monitoring/ensostuff/ensoyears.shtml).

\begin{tabular}{cll}
\hline \hline Basins (peak season) & \multicolumn{1}{c}{ High TCG season } \\
\hline WP (JASO) & $1984,1992,1994,2013$ & \multicolumn{1}{c}{ Low TCG season } \\
EP (JAS) & $1982^{\mathrm{b}}, 1984,1985,1987^{\mathrm{b}}, 1992,1994,2009,2014$ & $1998^{\mathrm{a}}, 2003,2008,2010^{\mathrm{a}}, 2014$ \\
NA (ASO) & $1995^{\mathrm{a}}, 1998^{\mathrm{a}}, 2000^{\mathrm{a}}, 2005,2010^{\mathrm{a}}, 2011^{\mathrm{a}}, 2012$ & $1979,1991^{\mathrm{b}}, 1996,1999^{\mathrm{a}}, 2010^{\mathrm{a}}, 2011^{\mathrm{a}}$ \\
SI (JFM) & $1986,1989^{\mathrm{a}}, 1994,2003^{\mathrm{b}}, 2008^{\mathrm{a}}$ & $1982^{\mathrm{b}}, 1983,1986^{\mathrm{b}}, 1992,1994,1997^{\mathrm{b}}$ \\
SP (JFM) & $1981,1983^{\mathrm{b}}, 1992^{\mathrm{b}}, 1997,1998^{\mathrm{b}}, 2010^{\mathrm{a}}, 2014$ & $1979,1980,1981,1983^{\mathrm{b}}$ \\
\hline
\end{tabular}

${ }^{\text {a }}$ Peak TC season that coincides with a La Niña event.

${ }^{\mathrm{b}}$ Peak TC season that coincides with an El Niño event.

while the relationship is weak in other basins. A majority of HTCG (LTCG) seasons over the NA show close association with concurrent La Niña (El Niño) phases, while a weak but reverse relationship is noticeable over the EP. In contrast, no direct association with ENSO phases is noted over the WP during HTCG, albeit $40 \%$ of LTCG seasons coincide with La Niña conditions. No clear relationship is found in the SI and SP during LTCG, although $40 \%$ of HTCG seasons in the SP are concurrent with $\mathrm{El}$ Niño events. It appears that TCG frequency over some basins is sensitive to concurrent ENSO conditions; however, extreme HTCG-LTCG can even occur in ENSOneutral conditions. Notable interdecadal variation in TCG frequency is also noted over the WP, EP, and NA, which could be related to a possible phase change in other climatic modes at interdecadal time scales (Vimont and Kossin 2007; Klotzbach and Gray 2008; Liu and Chan 2013; Caron et al. 2015), but this is beyond the scope of this study.

\section{b. Spatial changes in TCG frequency}

Figure 3 represents the observed spatial distribution of TCG frequency over individual ocean basins during peak seasons, including a 36-yr climatology (Fig. 3a), and anomalous changes during HTCG (Fig. 3b) and LTCG (Fig. 3c) seasons, respectively. The climatological TCG locations are mostly confined within a $10^{\circ}-20^{\circ}$

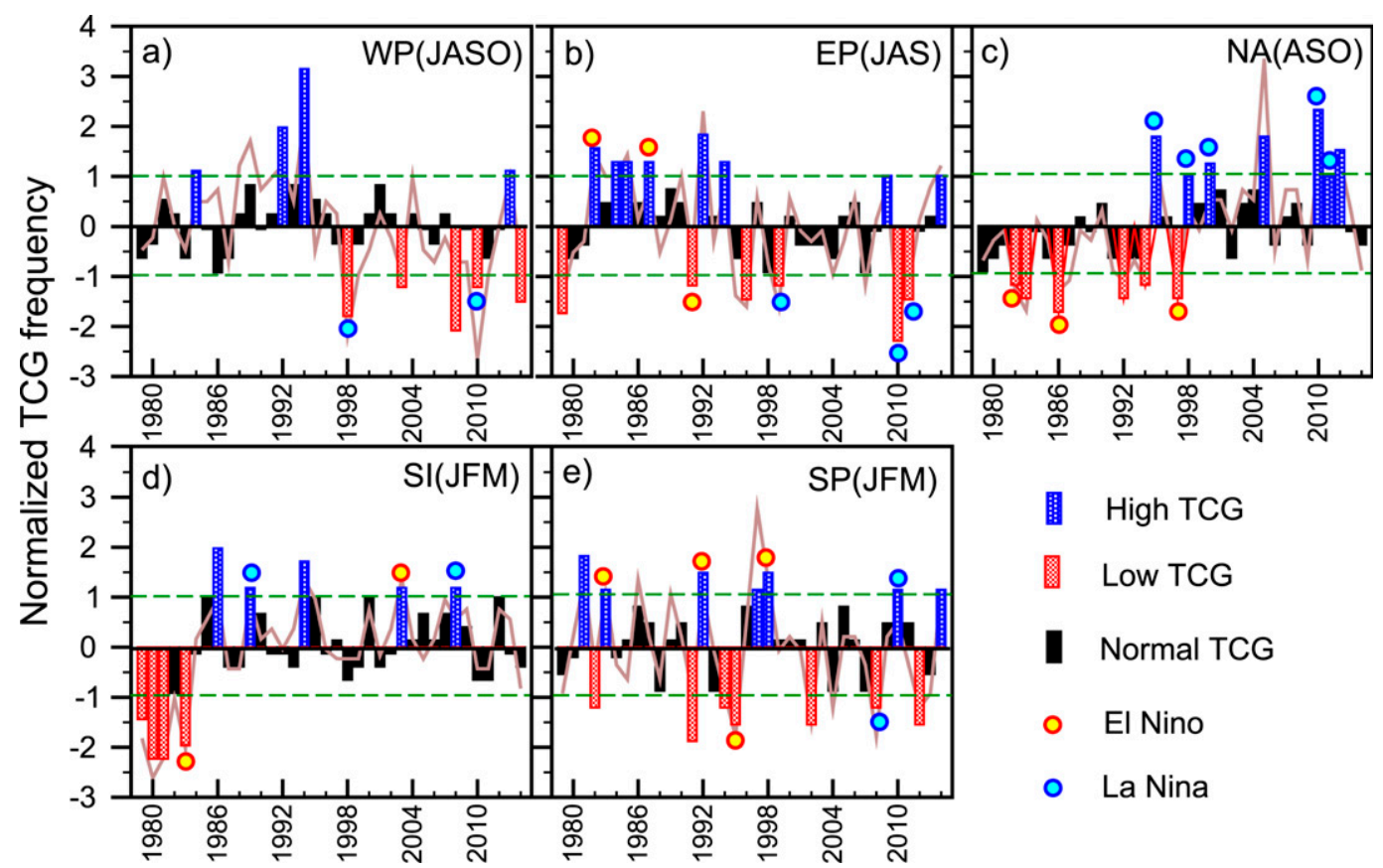

FIG. 2. Normalized time series of TCG frequency per peak seasons for individual ocean basins in the period 19792014. The high (low) TCG seasons are shown in blue (red) bars, relative to normal seasons (black bars). The brown curve shows the annual variation of normalized TCG frequency. The El Niño (La Niña) episodes (based on a threshold of above-below of \pm 0.5 for the oceanic Niño index) that coincide with these extreme TCG seasons are also marked with red (blue) circles. 
a. $\operatorname{Clim}(N T C G)$
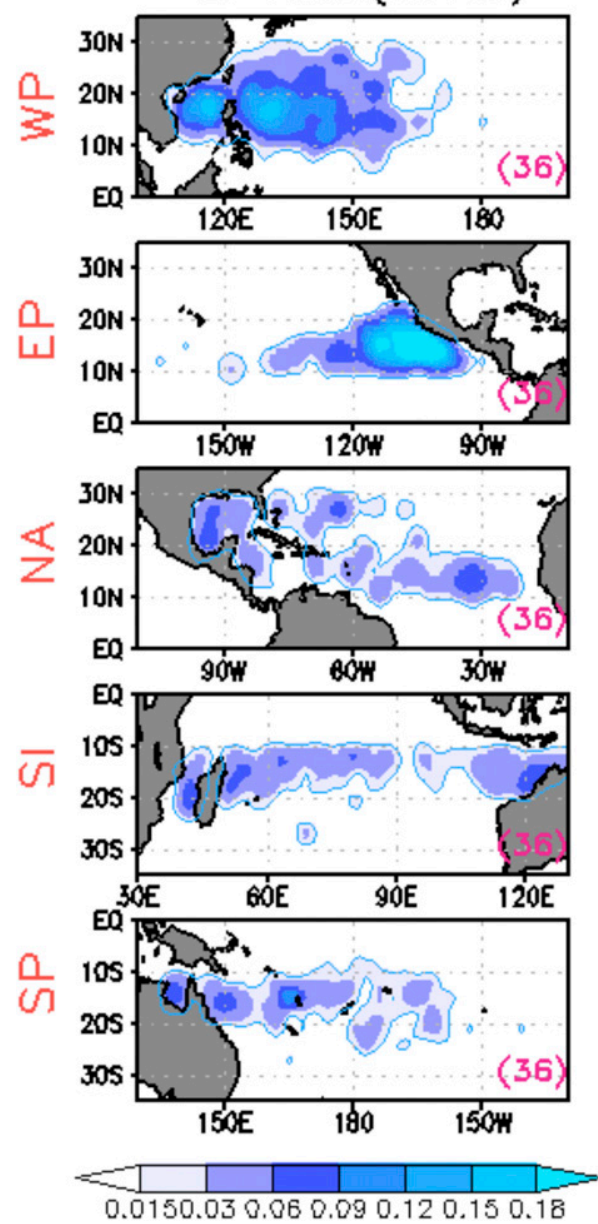
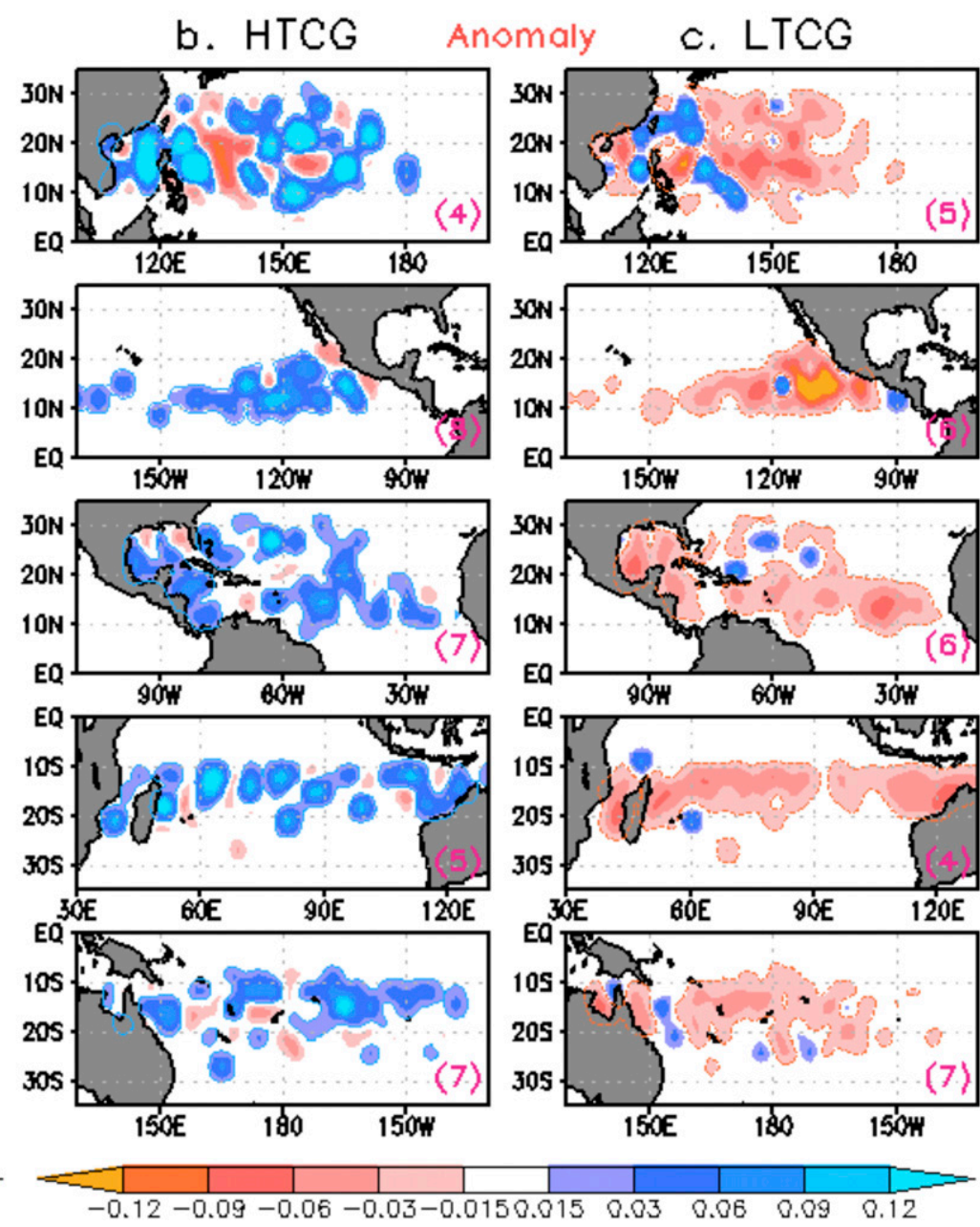

FIG. 3. Composite of observed spatial distribution of (left) TCG climatology (Clim) over individual ocean basins per $2^{\circ} \times 2^{\circ}$ grid box for peak seasons averaged over entire period (1979-2014) and for (center) anomalously high and (right) low TCG seasons. The number of peak TC seasons considered is shown in parentheses.

latitudinal belt over the EP, SI, and SP but extended poleward in the WP and NA. The geographically diverse and opposite anomalous changes in TCG during HTCG-LTCG seasons are well captured over the five basins. A marked longitudinally tripole pattern of anomalously high-low-high (low-high-low) TCG is observed during HTCG (LTCG) over the WP. Considerable enhancement (reduction) in TCG is noted around the main development region of the EP $\left(10^{\circ}-20^{\circ} \mathrm{N}, 135^{\circ}-\right.$ $\left.90^{\circ} \mathrm{W}\right)$ and the NA $\left(10^{\circ}-20^{\circ} \mathrm{N}, 60^{\circ}-15^{\circ} \mathrm{W}\right)$ during HTCG (LTCG) seasons. Over the SI, the locations of enhanced genesis are mainly observed around the central part and near the western coast of Australia during HTCG, while a systematic TCG decrease can be seen over the mean genesis locations during LTCG seasons. Over the SP, enhanced TCG is observed near the Australian continent and east of the date line extending up to $140^{\circ} \mathrm{W}$, in possible association with El Niño (Fig. 2e), consistent with previous studies (Kuleshov et al. 2008). However, TCG was largely reduced within most parts of the climatologically defined genesis domain during LTCG seasons.

Figure 4 displays the anomalous zonal (Fig. 4a) and meridional (Fig. 4b) shift of genesis locations during HTCG (blue) and LTCG (red) compared to climatological mean genesis location (black). Over the WP, enhanced TCG is noted both in the east and west parts of the climatological mean TCG locations during HTCG seasons, though TCG is largely reduced east of $140^{\circ} \mathrm{E}$ during LTCG, consistent with La Niña events (Chan 2000; Chia and Ropelewski 2002). Prominent TCG enhancement is also evident with a slight westward shift of the mean genesis location over the EP during HTCG. Similar substantial enhancement of TCG is noted in the main development region of the NA. An anomalous increase in TCG can be seen in the 
a. Zonal Distr.
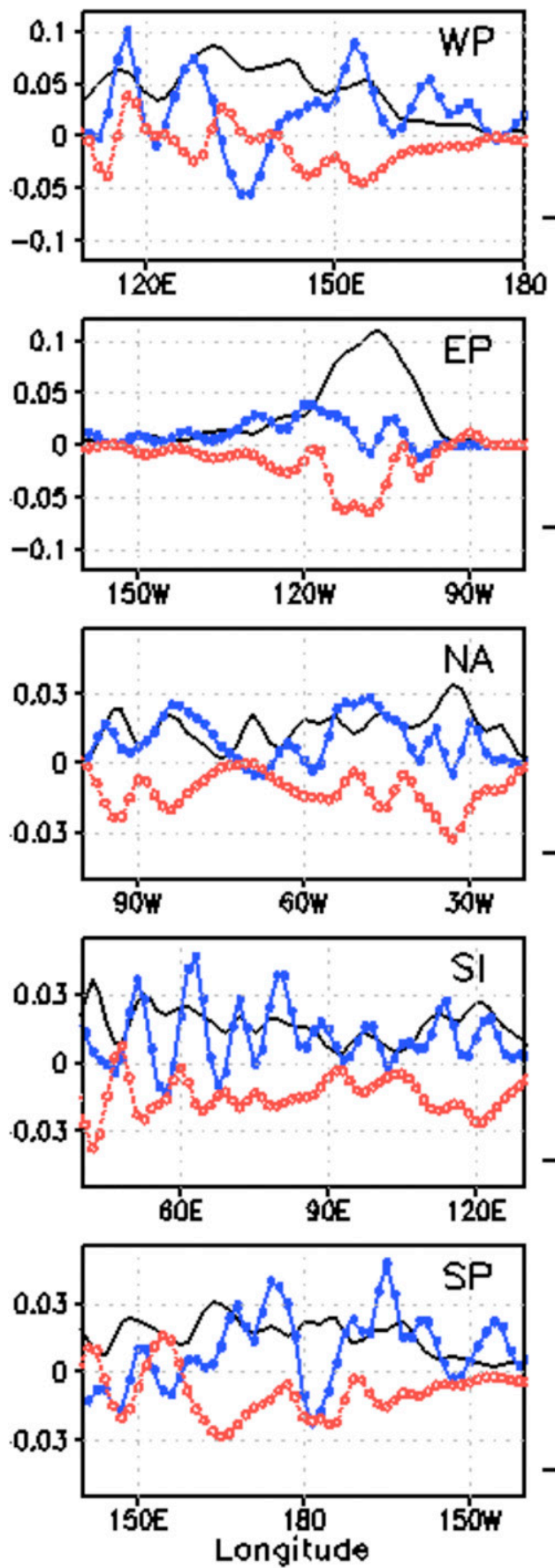

b. Merid, Distr.
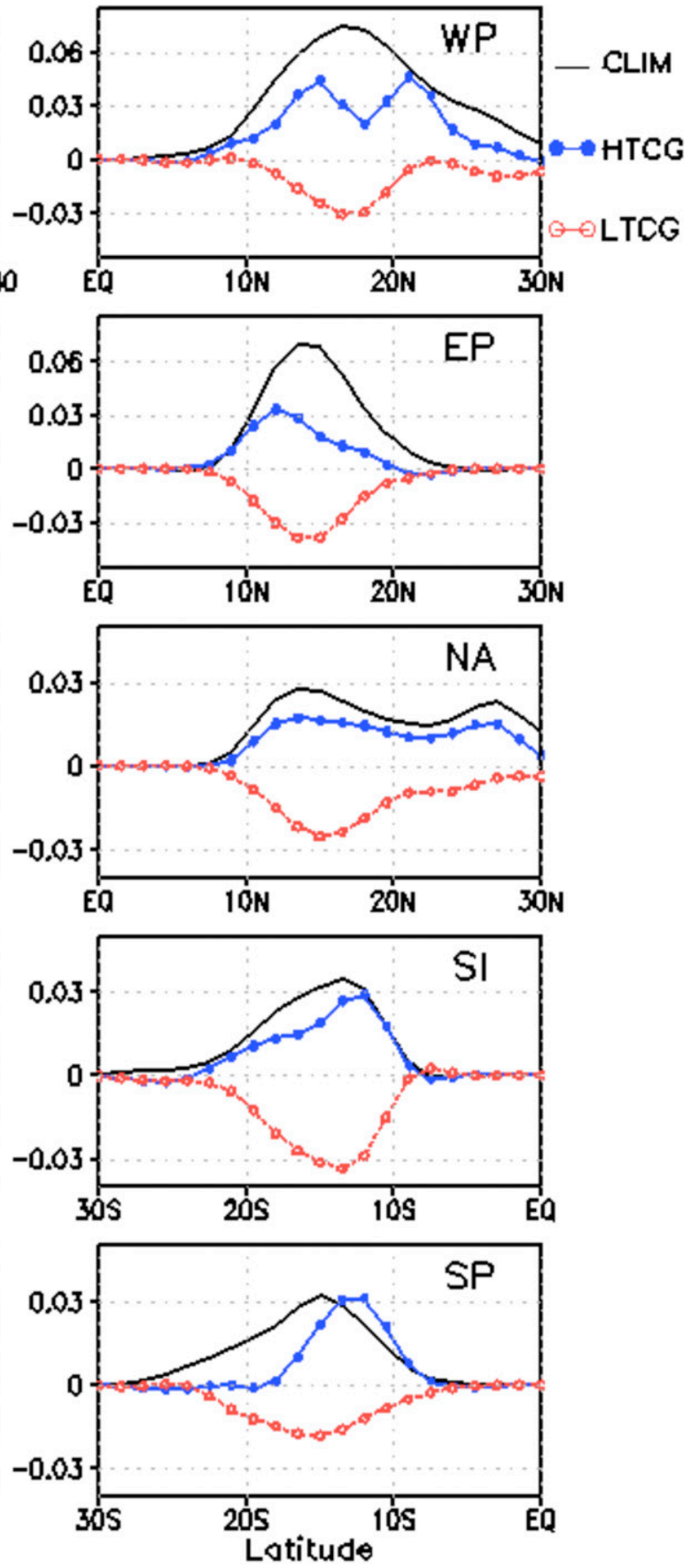

FIG. 4. Climatological distribution of TCG frequency (CLIM; black), and anomalous change during high seasons (HTCG; blue) and low seasons (LTCG; red): (left) averaged over $5^{\circ}-25^{\circ}$ latitudes as a function of longitude and (right) averaged over individual ocean basin longitudes as a function of latitude.

central part $\left(55^{\circ}-85^{\circ} \mathrm{E}\right)$ of the SI and to the east of $170^{\circ} \mathrm{W}$ of the SP basin during HTCG seasons, as evident in Fig. 3b. In addition, a prominent equatorward displacement of TCG can been noted in the EP, SI, and SP during HTCG, compared to its mean position
(Fig. 4b). However, no clear latitudinal change in enhanced TCG is noted in the NA during HTCG seasons.

Regarding the geographical shifts in the spatial patterns of TCG between high and low years, there are 


\section{Vertical Wind Shear (VWS)}

a. $\operatorname{Clim}(\mathrm{NTCG})$
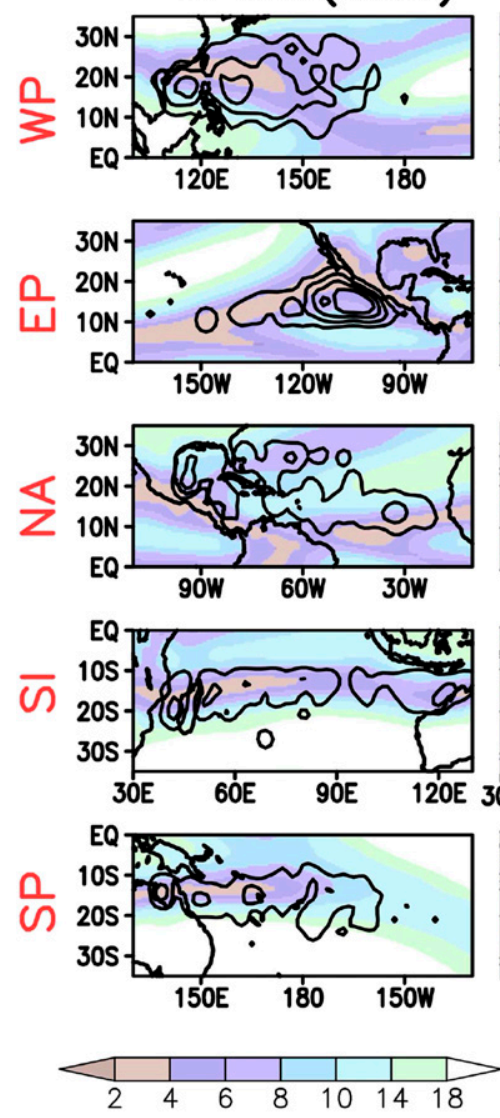

b. HTCG Anomaly c. LTCG
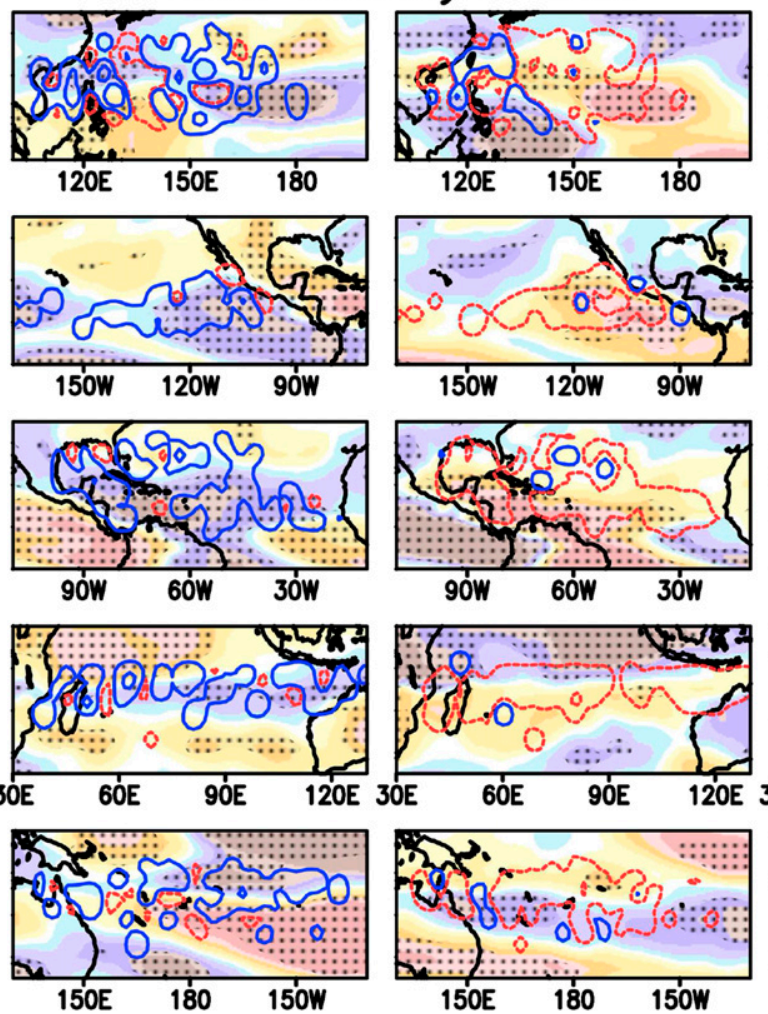

$$
\begin{array}{l|lll|l|l|l|l|l|l|l|l}
\hline & & & & & & & & & & \\
\hline-2.8 & -2.1 & -1.4 & -0.7 & -0.2 & 0.2 & 0.7 & 1.4 & 2.1 & 2.8 & \left(\mathrm{~ms}^{-1}\right)
\end{array}
$$

\section{d. HTCG-LTCG}
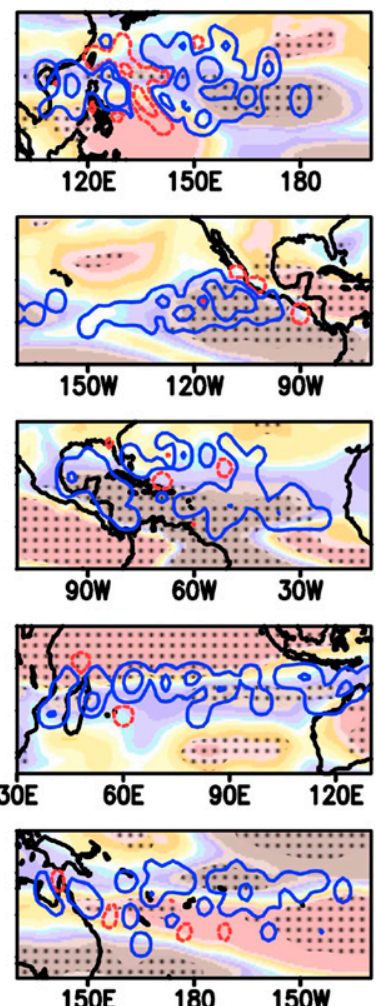

FIG. 5. Composite of large-scale VWS ( $\mathrm{m} \mathrm{s}^{-1}$; color shaded) of (a) long-term CLIM superimposed with observed spatial distribution of TCG (black contour), anomalous changes during (b) HTCG and (c) LTCG seasons and (d) the difference between HTCG and LTCG (HTCG - LTCG) over individual ocean basins. The VWS values significant above $95 \%$ confidence level are marked with dots. Similar to Fig. 2, the enhanced (reduced) TCG frequency is overlaid with blue (red) contours.

some similarities to the shifts associated with ENSO (Camargo et al. 2010) but some important differences also. Similarities include over the EP, where El Niño typically leads to a westward shift (Irwin and Davis 1999; Collins and Mason 2000; Chu and Zhao 2007), similar to the HTCG anomaly pattern. In the SP, El Niño causes an eastward movement in TCG formation regions, as also seen in the HTCG pattern, although the shift associated with El Niño is more equatorward than that associated with HTCG seasons. Other differences include over the SI basin, where El Niño usually leads to a westward shift (Kuleshov et al. 2009), whereas HTCG indicates rather a basinwide increase.

Next, we examine a suite of large-scale dynamic and thermodynamic conditions that are believed to affect TCG frequency, followed by the quantification of their potential contributions.

\section{Large-scale climate conditions associated with TCG frequency extremes}

\section{a. Spatial changes in dynamic climate conditions}

Figure 5 shows the composited VWS for climatology (Fig. 5a, shaded) overlain with the spatial distribution of TCG (black contour, as in Fig. 3), anomalies during HTCG (Fig. 5b) and LTCG (Fig. 5c) seasons, and their difference (Fig. 5d) superimposed with enhanced (blue contour) or reduced (red contour) TCG frequency changes in individual ocean basins, respectively. The overall TCG distribution is mostly collocated within weak VWS (less than about $10 \mathrm{~m} \mathrm{~s}^{-1}$ ) regions, except over the NA where the main formation region appears to overlap a region of much higher VWS. During HTCG, anomalously weak VWS coincides with the enhanced TCG locations, while the opposite situation is evident during LTCG seasons over almost all five ocean 


\section{Geopotential height ( $850 \mathrm{hPa}$ )}

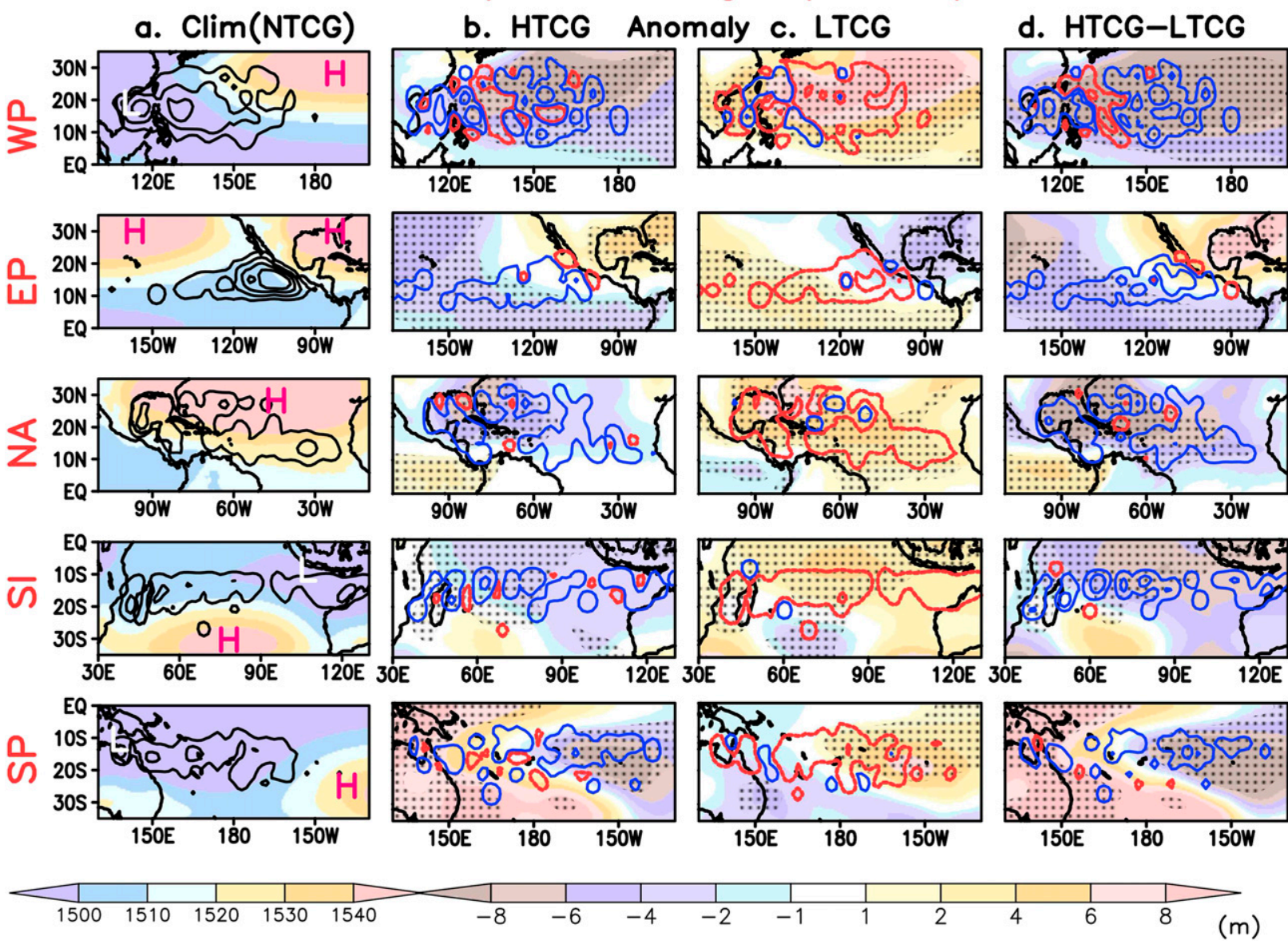

FIG. 6. As in Fig. 5, but for GPH (m; color shaded) at $850 \mathrm{hPa}$. Here climatological lows (highs) are denoted as L (H).

basins. The SP appears to be an exception, where the southern part of reduced TCG overlies with weak VWS. The difference between HTCG and LTCG further shows the presence of statistically significant weak VWS almost collocated with enhanced TCG, emphasizing the dominant role of seasonal VWS for this asymmetry in TCG frequency during peak TC seasons.

Previous studies found that the mean position and strength of seasonal large-scale circulation can substantially regulate the TC formation rate during peak seasons. Similarly to Fig. 5, the seasonal composites of geopotential height (GPH) at $850 \mathrm{hPa}$ (shaded) and lowlevel $(850 \mathrm{hPa})$ large-scale rotational wind (vectors) are shown in Figs. 6 and 7, respectively. In the WP, SP, and SI, the westerlies and associated monsoon trough are the main components of the seasonal wind circulation, forming a confluence zone that provides an ideal environment for TC formation (Briegel and Frank 1997; Ritchie and Holland 1999). In contrast, the easterly trades dominate over the EP, and the subtropical highs occupy the majority of the NA basin. During HTCG seasons (Figs. 6b and 7b), strengthening of the anomalous cyclonic circulation and concomitant negative GPH anomaly is evident over most parts of the tropical basins, providing conditions conducive for TC formation. The circulation features are essentially opposite during LTCG seasons (Figs. 6c and 7c), contributing toward overall suppression of TC formation. In particular, significantly strong cyclonic (anticyclonic) circulation anomalies are noticeable coexisting with enhanced (reduced) TCG over the WP, NA, SI, and SP during HTCG (LTCG) seasons.

Concomitant large-scale low-level cyclonic (anticyclonic) vorticity (Fig. 8) is noticeable in association with anomalously strong low-level westerlies (easterlies) in the enhanced (suppressed) TCG locations over most of the basins, in particular over the SP, but is slightly ambiguous over the EP. These results indicate that significant weakening (strengthening) of the climatological subtropical high over the central Pacific (northwest 


\section{Rotational Wind ( $850 \mathrm{hPa}$ )}
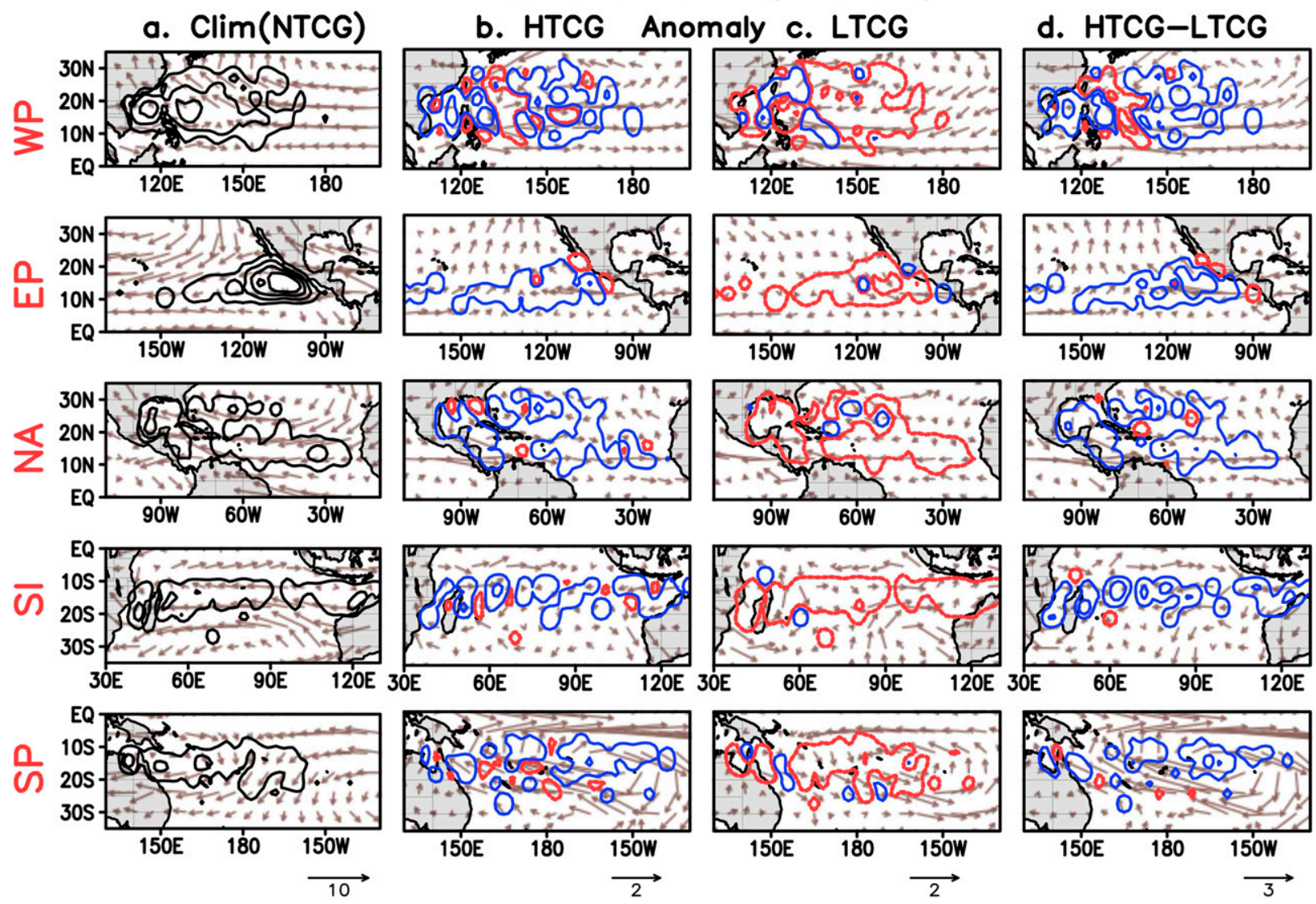

$\left(m s^{-1}\right)$

FIG. 7. As in Fig. 5, but for low-level Rwind ( $\mathrm{m} \mathrm{s}^{-1}$; vectors).

Atlantic) may favor TCG over the WP (NA). Similarly, enhanced TCG over the EP is linked with anomalous strengthening of the climatological subtropical high in the northwest Atlantic, consistent with anomalous weakening of the subtropical ridge over the northwest Pacific. Conversely, during LTCG seasons, the low-level anomalous anticyclonic circulation may further be facilitated by the anomalous equatorward extent of the subtropical high that could enhance tropical easterly anomalies. This could substantially amplify the VWS, which potentially suppresses convective activity, leading to a large reduction in the TCG frequency over the respective ocean basins. As a result, the monsoon trough becomes much weaker over the WP, SI, and SP, leading to very low TC activity. In contrast, the subtropical high tends to be much weaker and more poleward during HTCG. Its influence is less pronounced on the tropical winds, and equatorial westerlies could penetrate more northeastward, resulting in a stronger monsoon trough and favorable conditions for TCGs. Therefore, the combined effect of the large-scale tropical circulation and subtropical high may explain the TCG extremes in most of the basins.

The changes in the large-scale conditions are also directly linked with upward mass flux (Held and Zhao 2011) that show close association with the global-scale changes in TCG frequency (Fig. S1 in the supplemental material). The climatological distribution of TCG generally follows the large-scale midtroposphere ascending vertical motion $(\omega$ at $500 \mathrm{hPa}$; negative values represent ascending motion). During HTCG an anomalous increase in TCG (blue contour) mostly occurs within the basinwide ascending anomalies indicated by significantly negative anomalies of $\omega$ over most of the basins. The spatial distribution of reduced TCG corresponds reasonably well with the regions of enhanced midtroposphere vertical descent during LTCG, with weak association in some parts of the WP, SP, and SI. It is important to note here that the ascending $\omega$ at 


\section{Relative Vorticity ( $850 \mathrm{hPa}$ )}
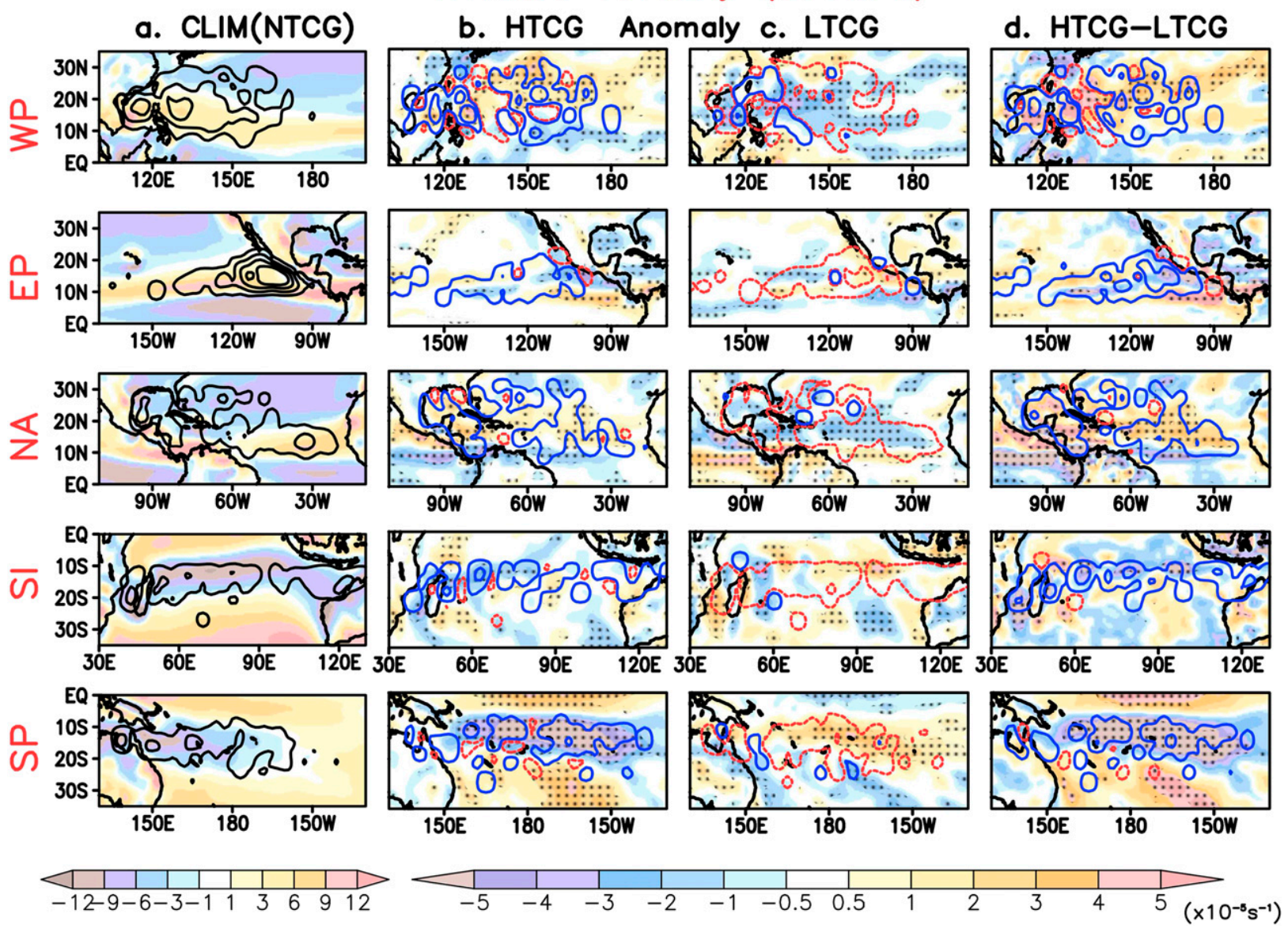

FIG. 8. As in Fig. 5, but for low-level RVor at $850 \mathrm{hPa}\left(10^{-5} \mathrm{~s}^{-1}\right.$; color shaded).

$500 \mathrm{hPa}$ in fact reflects the amount of convection and thus the occurrences of TCs also. However, the fractional contribution of TCs to the mean upward motion (which is comparable to their fractional contribution to rainfall) is quite small $(3 \%-7 \%)$ in nearly all the major genesis basins (e.g., Jiang and Zipser 2010). A reasonable coherent relationship with the changes in other dynamic conditions thus supports the idea that upward mass flux could play a critical role in modulating TCG frequency over tropical ocean basins in association with the tropical atmospheric circulation.

The above results suggest that substantial variations in large-scale dynamic conditions have important influences in modulating TCG frequency over individual basins, but with significant differences in regional controls from basin to basin. Since such changes in dynamic conditions may not be independent of the changes in thermodynamic conditions (Frank 1987), the influence of large-scale thermodynamic conditions on TCG frequency is discussed next.

\section{b. Spatial changes in thermodynamic climate conditions}

The seasonal composites of SST are presented in Fig. 9. Given that high SST is important for TCG (Dare and McBride 2011), it is evident that the seasonal distributions of TCG over different ocean basins are essentially confined to the regions of SST above $26.5^{\circ} \mathrm{C}$, consistent with the existing theories. Basinwide anomalous warming (cooling) is observed over the EP and NA basins during HTCG (LTCG) seasons, in close association with concurrent ENSO events (Figs. 2b,c). Such significant positive (negative) changes in SST anomaly further induce (reduce) favorable (unfavorable) environmental conditions for TCG, consistent with locations of enhanced (reduced) TCG during HTCG (LTCG). However, such close association between local SST variation and TCG is surprisingly 


\section{Sea Surface Temperature (SST)}

a. $\operatorname{Clim}($ NTCG)
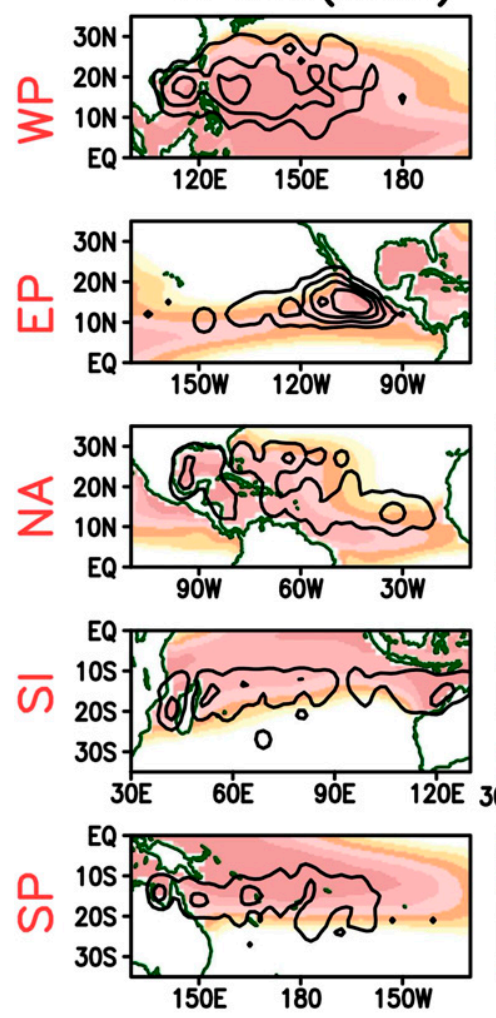

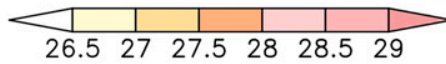

b. HTCG Anomaly c. LTCG
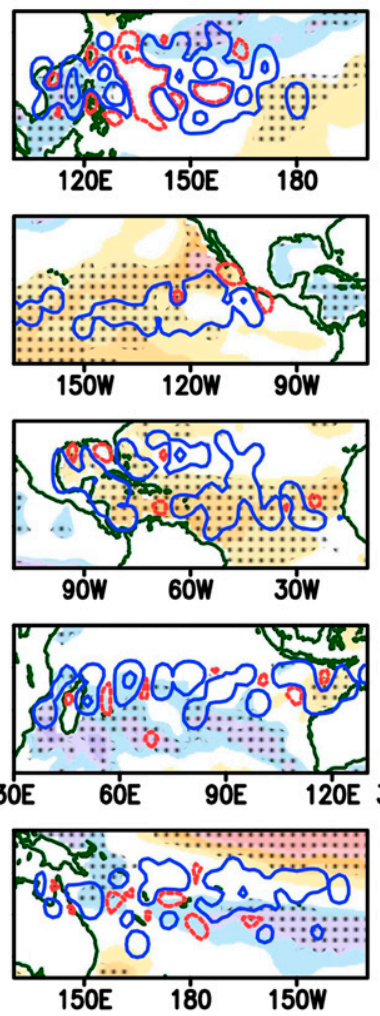

d. HTCG-LTCG
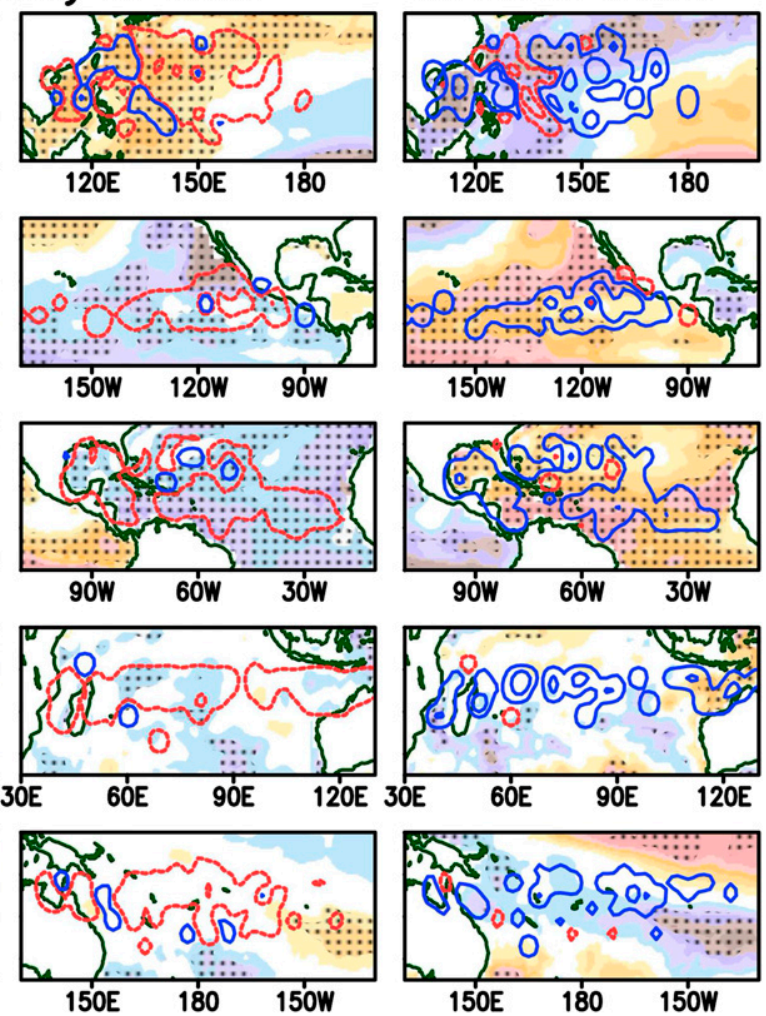

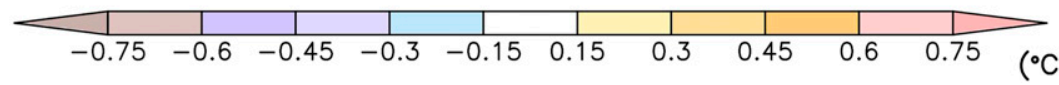

FIG. 9. As in Fig. 5, but for SST $\left({ }^{\circ} \mathrm{C}\right.$; color shaded).

missing in other ocean basins. Over the SI, the SST is anomalously negative in some part of the enhanced TCG regions (except near western Australia); however, the difference shows an anomalously weak warming north of $15^{\circ} \mathrm{S}$, which could provide some positive impact on TCG frequency. Over the WP, the local SST is anomalously negative in the vicinity of enhanced TCG during HTCG, while the anomalous increase in local SST is associated with decreased TCG over the WP during LTCG. This suggests that the local variation in seasonal SST may have relatively small or negligible contributions toward modulating TCG frequency over the WP, consistent with previous studies (Chan and Liu 2004; Vecchi and Soden 2007). However, relatively cooler SST can also be seen east of $150^{\circ} \mathrm{E}$ near the equatorial central Pacific region as $40 \%$ of LTCG seasons in the WP, concurrent with La Niña events (Fig. 2a). Such remote changes in SST may partly influence the existing dynamic factors conducive for TCG frequency change (Chia and Ropelewski 2002). Similar to the WP, no coherent relationship is observed between enhanced (reduced) TCG and local SST over the SP during the extreme TCG seasons. Such a relatively weak relationship between local SST and TCG frequency indicates that the changes in local SST may be of minor importance to observed changes in TCG frequency over the SP basin as well. It may be anticipated that the asymmetric migration of the monsoon trough, along with anomalous shift of the subtropical high (Figs. 6 and 7), could play vital roles in inducing largescale dynamic conditions favorable for TCG over these basins. Nonetheless, warm SST anomalies east of $170^{\circ} \mathrm{W}$ and near the central-eastern equatorial Pacific are evident, as $\sim 40 \%$ of HTCG seasons over the SP are concomitant with El Niño events (Fig. 2e). Such an extended anomalous warm water region could remotely contribute to the equatorward displacement in TCG during HTCG (Fig. 4). The seasonal changes in midlevel RH during HTCG and LTCG were also compared with TCG variations but found to be inconsistent 


\section{Maximum Potential Intensity (MPI)}

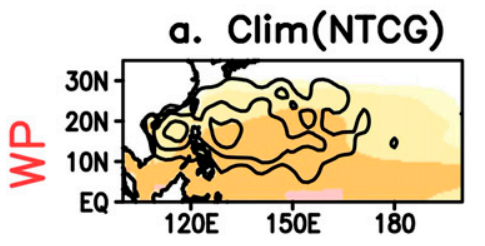

b. HTCG Anomaly c. LTCG
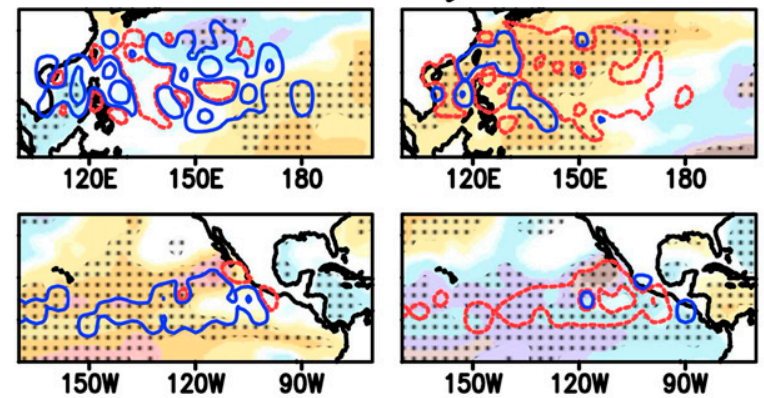

150w 120W 9ów
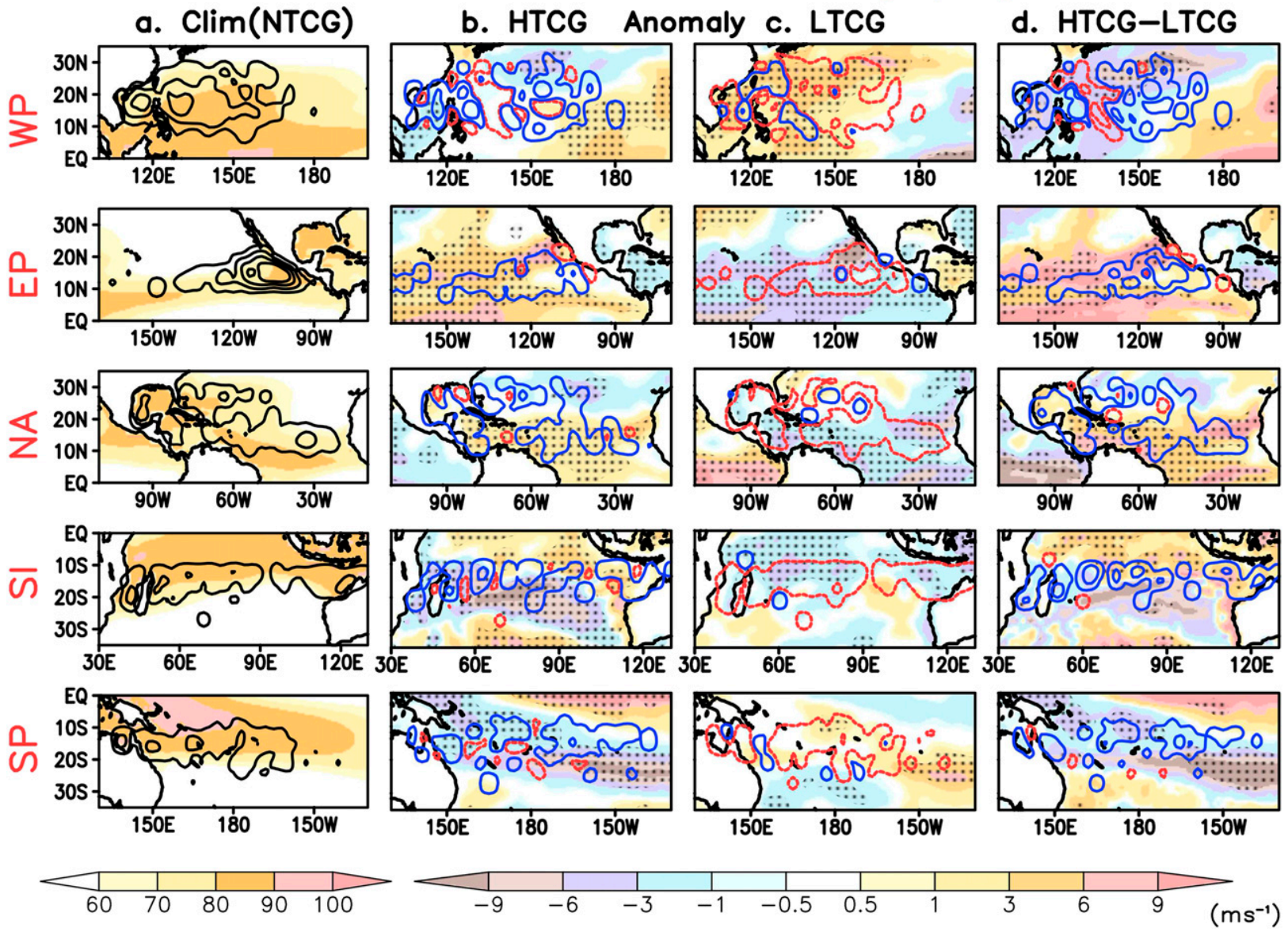

FIG. 10. As in Fig. 5, but for MPI ( $\mathrm{m} \mathrm{s}^{-1}$; color shaded).

between basins (Fig. S2 in the supplemental material). The enhanced TCG are associated with higher RH in some basins (EP, NA, and SI), but no direct association could be found in the WP and SP, especially during LTCG seasons. This suggests that the variation in midlevel RH is likely to play only a secondary role in controlling TCG frequency.

There are well-known associations between MPI and SST (Vecchi and Soden 2007), and MPI is also found closely related to the observed TC intensity (Holland 1997). To find out its relationship with TCG frequency, we examine the seasonal distribution of MPI (Fig. 10). Climatological high MPI values of roughly $70 \mathrm{~m} \mathrm{~s}^{-1}$ (Fig. 10a) are evident coexisting with the mean TCG in almost all basins. During HTCG (Fig. 10b), a significant positive MPI anomaly is noted over the EP and NA and at latitudes equatorward of about $10^{\circ} \mathrm{S}$ in the SI in the areas of enhanced TCG, indicating that MPI favors promoting TCG over these basins. In contrast, the MPI is anomalously negative over the locations of enhanced TCG in the WP and SP, indicating that there is almost no relationship between local MPI and TCG frequency in these basins, consistent with SST changes (Fig. 9b).

The mean-flow-driven low-level MFC could be another environmental factor that combines both the effects of large-scale converging winds and moisture advection (Neelin and Held 1987). Thus, MFC has the potential to influence the variation in TCG frequency. The spatial distribution of low-level MFC is shown in Fig. 11. The TCG is located roughly $5^{\circ}$ latitude poleward of the near-equatorial longitudinal belt of climatological MFC maxima in most ocean basins (Fig. 11a). During HTCG (Fig. 11b), anomalously increased TCG is nearly collocated with enhanced MFC anomalies over most of the basins, except over the EP, possibly due to a weak association with the large-scale relative vorticity (Fig. 8b). A strong latitudinal gradient of MFC is noted over the SP during HTCG, coupled with enhanced warming (Fig. 9b) and concomitant with 


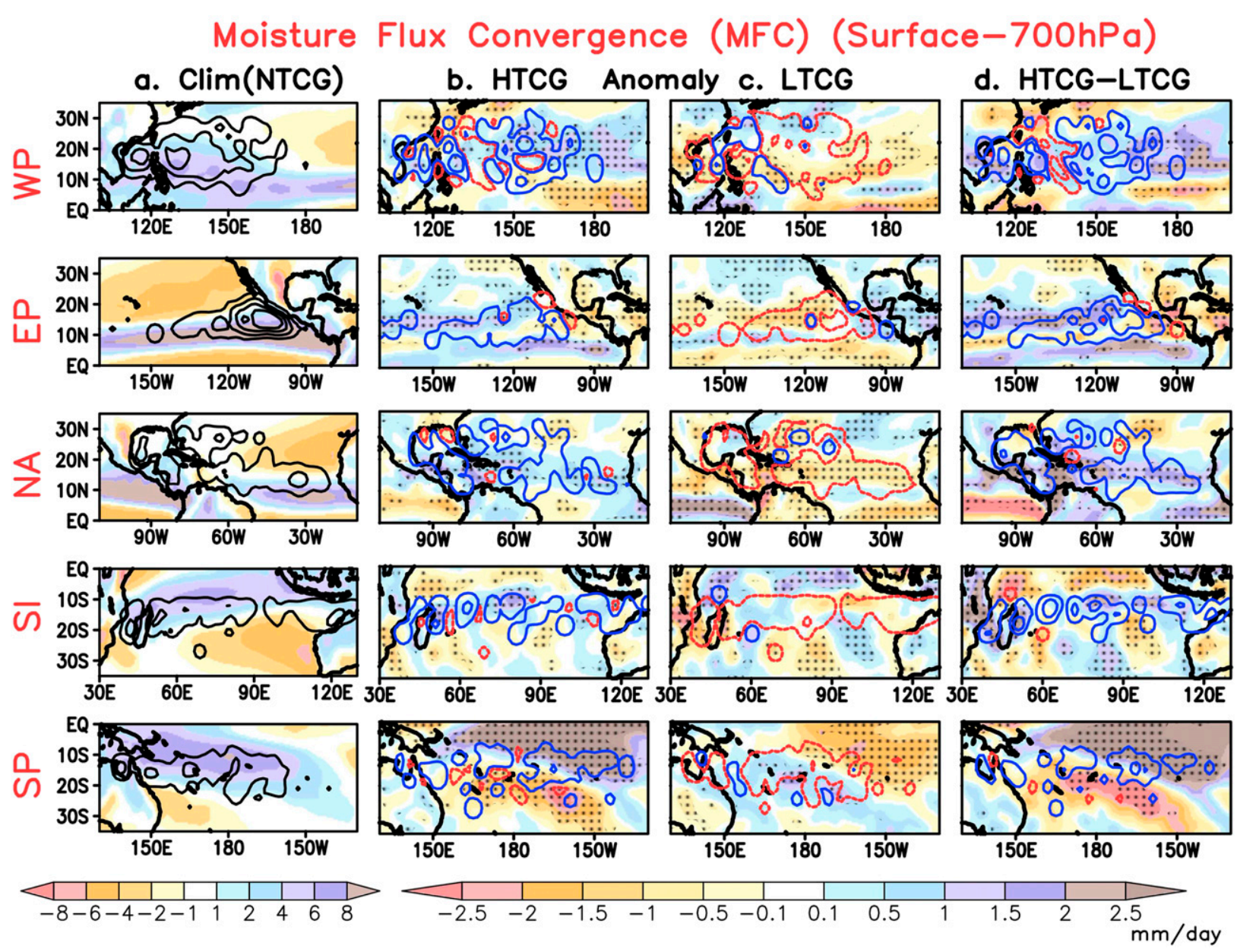

FIG. 11. As in Fig. 5, but for low-level (surface-700 hPa) MFC (mm day ${ }^{-1}$; color shaded).

the eastward migration of enhanced TCG. Similarly, the reduced TCG corresponds reasonably well with the regions of reduced MFC during LTCG (Fig. 11c), except over the central part of the SI, and poleward of TCG locations in the WP and SP. Although the direct association between midlevel RH and TCG frequency in most parts of the WP and SP is opposite to that expected, the positive MFC anomalies over TCG locations could considerably amplify the likelihood of TCG by allowing large-scale moisture advection through anomalously strong low-level convergence (Fig. 7d). These results suggest that the MFC may have a positive impact on TCG frequency over most of the ocean basins, largely driven by the associated dynamic conditions.

Table 3 summarizes the large-scale climate conditions and their corresponding anomalous change in sign over the genesis locations during HTCG and LTCG. It shows that there are some differences between basins in the sign of the influence of the various parameters. For instance, for the WP, while it is not surprising that TC formation is favored by decreased VWS, cyclonic lowlevel winds, increased vorticity, more upward vertical velocity, and MFC, the negative relationship with SST and MPI is more surprising. Note that in this basin, midlevel RH does not appear to affect TC formation rates between high and low seasons. In contrast, basins that are strongly influenced by ENSO (e.g., the EP and NA) have increased TC numbers with increased SST and MPI and also have higher RH during HTG seasons (figure not shown). Relationships between TCG and SST (as well as MPI) are also quite ambiguous in the WP, SP, and SI basins.

c. Quantification of genesis-weighted changes in large-scale climate conditions

It is crucial to quantify the distinct competing effects of potentially relevant large-scale climate conditions on TCG frequency. Therefore, we computed the genesisweighted changes in different climate conditions during 
TABLE 3. Summary of large-scale climate conditions used and their corresponding change in sign over TCG location. Here, C (A) denotes cyclonic (anticyclonic) circulation.

\begin{tabular}{|c|c|c|c|c|c|c|c|c|c|}
\hline \multirow[b]{2}{*}{ Ocean basins } & \multicolumn{9}{|c|}{ Environmental variables and their corresponding change in sign } \\
\hline & HTCG/LTCG & VWS & Wind rotation $(850 \mathrm{hPa})$ & $\mathrm{RV}$ or $(850 \mathrm{hPa})$ & $\omega(500 \mathrm{hPa})$ & SST & RH & MPI & MFC \\
\hline \multirow[t]{2}{*}{ WP } & HTCG & - & $\mathrm{C}$ & + & - & - & + & - & + \\
\hline & LTCG & + & A & - & + & + & + & + & - \\
\hline \multirow[t]{2}{*}{ EP } & HTCG & - & $\mathrm{C}$ & + & - & + & + & + & + \\
\hline & LTCG & + & A & - & + & - & - & - & - \\
\hline \multirow[t]{2}{*}{ NA } & HTCG & - & $\mathrm{C}$ & + & - & + & + & + & + \\
\hline & LTCG & + & A & - & + & - & - & - & - \\
\hline \multirow[t]{2}{*}{ SI } & HTCG & - & $\mathrm{C}$ & $-(+\mathrm{SH})$ & - & - & + & + & + \\
\hline & LTCG & + & A & $+(-\mathrm{SH})$ & + & - & - & - & - \\
\hline \multirow[t]{2}{*}{ SP } & HTCG & - & $\mathrm{C}$ & $-(+\mathrm{SH})$ & - & + & - & - & + \\
\hline & LTCG & + & A & $+(-\mathrm{SH})$ & + & + & + & + & - \\
\hline
\end{tabular}

HTCG and LTCG, following the method of Held and Zhao (2011). We define an average in which any largescale climate condition $A$ given as a spatial and seasonal mean over TCG locations is weighted by the spatial pattern of TCG $G$ :

$$
\langle A\rangle_{G} \equiv \frac{\overline{A \times G}}{\bar{G}},
$$

where the overbar indicates the average over the peak season. The genesis weighting provides a compact way of defining the direction of the change in the most relevant large-scale climate conditions over particular TCG regions. The fractional changes $\langle\delta A\rangle_{G} /\langle A\rangle_{G}$ in the genesis-weighted climate variables are calculated, areaaveraged over the genesis location during HTCG and LTCG seasons compared to climatology (Fig. 12).
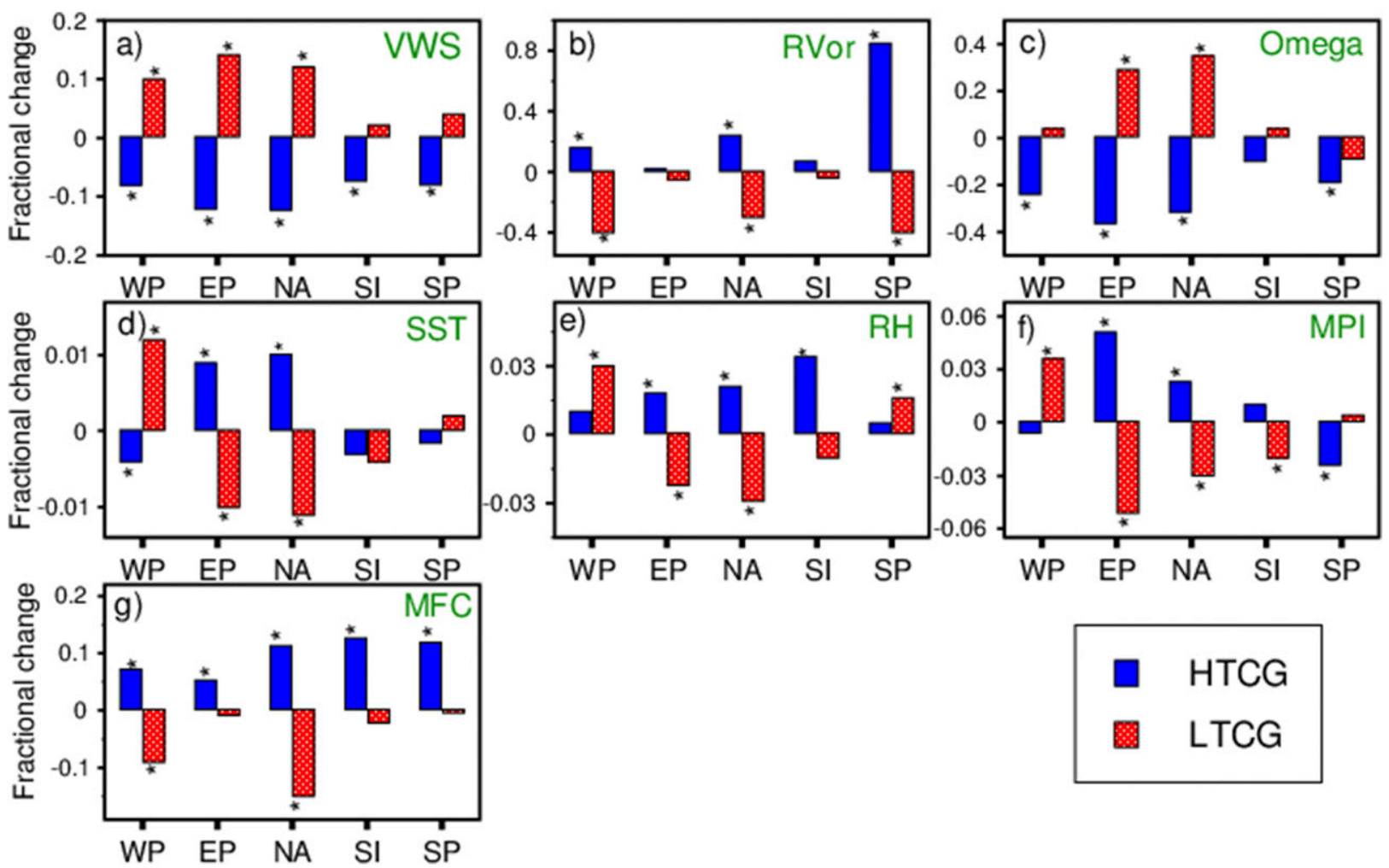

FIG. 12. Fractional changes in TC genesis-weighted large-scale dynamic and thermodynamic climate conditions averaged over individual ocean basins for HTCG (blue) and LTCG (red) seasons, respectively. The values significant above the $95 \%$ confidence level are marked with asterisks. 
Distinct regional differences in the genesis-weighted fractional change in large-scale conditions are noted among the basins, consistent with the above analyses. The genesis-weighted dynamic conditions exhibit a high variation ranging from $5 \%$ to $80 \%$ relative change, while changes in genesis-weighted thermodynamic conditions show roughly $0.5 \%-5.5 \%$ change among the basins but are still significant in some regions. Over the WP, the enhanced (suppressed) TCG frequency during HTCG (LTCG) can be primarily attributed to an approximately $-10 \%(+10 \%)$ change in VWS (Fig. 12a), along with a $+20 \%(-40 \%)$ change in low-level RVor (Fig. 12b) and a $22 \%(-5 \%)$ increase in convective activity (Fig. 12c), accompanying an $8 \%-10 \%$ change in MFC over TCG locations. However, the sign of the changes in genesis-weighted SST (Fig. 12d), MPI (Fig. 12e), and RH (Fig. 12f) are inconsistent between basins with the changes in TC formation rate. The variable with the most consistent relationship with genesisweighted TC formation is VWS, where in all basins the TC formation rate increases with lower VWS and decreases with greater VWS. Almost all of these VWS changes are statistically significant above the $95 \%$ confidence level. The next strongest relationships are with MFC and RVor, where the signs are also consistent across basins but slightly less significant than VWS. In contrast, the signs are not consistent for SST, RH, and MPI. This indicates that the local changes in thermodynamic conditions do not necessarily control the changes in TC formation rate at seasonal time scales. Regionally, the relative contributions of dynamic and thermodynamic conditions vary significantly. Over the WP, dynamic conditions dominate, as they do over the SP, where RVor could be considered the most dominant factor for the contrast in TC formation rate, with almost $+80 \%$ $(-40 \%)$ relative change during HTCG (LTCG). Conversely, the changes in TC formation rate over the EP and NA are influenced by a combination of dynamic and thermodynamic changes, although RVor plays the least role over the EP. Over the SI, although the fractional changes in SST are negative during HTCG, the increase in midlevel RH and MPI in combination with significantly weaker VWS could enhance MFC (+13\%), providing a favorable environment for high TC formation. Overall, the changes in observed TC formation rate over the WP and SP can be primarily attributed to the changes in dynamic conditions only, while TCG frequency over the rest of the basins depends on the combination of both the large-scale dynamic and thermodynamic changes. However, it is also important to remember that all these climate conditions are actually correlated and therefore do not regulate TCG frequency independently (Frank 1987). To distinguish their associations during TCG extremes, sensitivity experiments using numerical models will be necessary and will be addressed in a future study.

\section{Discussion and concluding remarks}

A theoretical foundation that can estimate the observed changes in TCG frequency from the mean climate state is still elusive. To fill this gap, the present study attempts to provide a comprehensive summary of how the extreme high-low variability of the TCG frequency during peak seasons over different ocean basins is strongly interrelated to the distinct changes in large-scale climate conditions at regional scales. Investigations are particularly focused on addressing the competing influence of large-scale dynamic versus thermodynamic climate conditions on observed changes in TC formation rate during contrasting peak seasons.

Based on the observed IBTrACS data, we identified peak TC seasons of significantly high and low TCG frequency for five major ocean basins, namely, western Pacific (WP), eastern Pacific (EP), North Atlantic (NA), south Indian Ocean (SI), and South Pacific (SP), and their spatial TCG changes are noted. To investigate the physical causes behind these observed changes in TCG frequency, composites of various potentially relevant large-scale dynamic conditions (such as vertical wind shear, low-level relative vorticity, low-level rotational wind, midtroposphere $\omega$ ) and thermodynamic conditions (such as SST, midlevel relative humidity and maximum potential intensity), along with vertically integrated moisture flux convergence are analyzed. Statistically significant and regionally differing changes in specific large-scale dynamic and thermodynamic conditions are noted concomitant with the spatial changes in the extreme seasons of TCG frequency over different basins. To summarize the competing individual contributions of the large-scale climate conditions on the distinct regional differences in the TCG, a quantitative approach based on genesisweighted fractional change has been formulated. Results from the analyses indicate that large-scale vertical wind shear could be considered as one of the dominant dynamic factors controlling the TCG frequency. The low-level relative vorticity is also regionally important over the WP, NA, and SI, and in particular it is the most dominant factor over the SP. In contrast, the signs of the changes in genesis-weighted SST, relative humidity, and maximum potential intensity are inconsistent with the changes in TC formation rate over both the WP and SP basins, where it might be expected from previous work that these variables would be positively 
correlated with TCG. This supports the idea that the local changes in thermodynamic conditions do not necessarily control the changes in TC formation rate over WP and SP during peak seasons. In particular, the results suggest that the variations in the large-scale dynamic conditions are in fact indispensable for the contrasting changes in TCG frequency over these two basins, while a combination of both dynamic and thermodynamic climate conditions is necessary for the contrasting changes in TCG frequency over other basins during TC active seasons. Such a distinctive association between large-scale climate and $\mathrm{TC}$ formation rate in different basins also highlights the issue of reformulating the existing empirical TC genesis potential indices for assessing changes in TCG frequency over individual basins.

The results shown here are relevant to the development of a climate theory of tropical cyclone formation, if such a theory is ever convincingly demonstrated. Presumably, a consistent theory would have similar relationships in all $\mathrm{TC}$ formation regions between values of large-scale climate variables and the rate of tropical cyclone formation. The fact that some of the variables examined here appear to have inconsistent relationships with $\mathrm{TC}$ formation between the various formation regions suggests that these particular variables may not form an important part of such a climate theory. Alternatively, this inconsistency could be caused by some variables only having a threshold relationship to TC formation. For instance, relative humidity is one of the variables shown here to have inconsistent relationships with TC formation between the basins (Fig. 12), and some previous work has implied that this variable only has a threshold relationship with TC formation (e.g., Bruyère et al. 2012; Dowdy et al. 2012). This would imply that values of such variables would have a weaker relationship to variations in $\mathrm{TC}$ formation rate, where values of variables beyond a defined threshold do not increase the likelihood of cyclogenesis. Furthermore, most of the recent genesis indices do not consider the distinct contributions of the dynamic and thermodynamic conditions over different basins, which may degrade the indices' capacity to replicate the observed interannual variability of TCG frequency (e.g., Bruyère et al. 2012). Therefore, the present study points out that revision of the existing indices could be necessary by utilizing a few large-scale predictors, depending on their independent contributions on modulating TCG frequency over individual basins. This concept was not explicitly tested here, however.

Nevertheless, the results from this study provide a global summary of the crucial climate links with the contrasting TCG frequency at regional scales and may have implications for the formulations of empirical indices for estimating TCG frequency over individual basins.

Acknowledgments. This research work is funded by the Australian Research Council (ARC) Discovery Project (Grant DP150102272). The authors acknowledge Prof. Suzana Camargo for useful discussions and Prof. Ian Simmonds for helpful comments on the earlier version of manuscript. The authors thank the editor and the anonymous reviewers for their insightful comments and suggestions on the earlier version of manuscript that have improved the quality of the paper.

\section{REFERENCES}

Basher, R. E., and X. Zheng, 1995: Tropical cyclones in the southwest Pacific: Spatial patterns and relationships to Southern Oscillation and sea surface temperature. J. Climate, 8, 1249-1260, doi:10.1175/1520-0442(1995)008<1249:TCITSP > 2.0.CO;2.

Bister, M., and K. A. Emanuel, 1998: Dissipative heating and hurricane intensity. Meteor. Atmos. Phys., 50, 233-240, doi:10.1007/ BF01030791.

Briegel, L. M., and W. M. Frank, 1997: Large-scale influences on tropical cyclogenesis in the western North Pacific. Mon. Wea. Rev., 125, 1397-1413, doi:10.1175/1520-0493(1997)125<1397: LSIOTC $>2.0 . \mathrm{CO} ; 2$.

Bruyère, C. L., G. J. Holland, and E. Towler, 2012: Investigating the use of a genesis potential index for tropical cyclones in the North Atlantic basin. J. Climate, 25, 8611-8626, doi:10.1175/ JCLI-D-11-00619.1.

Camargo, S. J., and A. H. Sobel, 2005: Western North Pacific tropical cyclone intensity and ENSO. J. Climate, 18, 29963006, doi:10.1175/JCLI3457.1.

— , and S. M. Hsiang, 2015: Tropical cyclones: From the influence of climate to their socioeconomic impacts. Extreme Events: Observations, Modeling, and Economics, Geophys. Monogr., Vol. 214, Amer. Geophys. Union, 303-342.

, K. A. Emanuel, and A. H. Sobel, 2007: Use of a genesis potential index to diagnose ENSO effects on tropical cyclone genesis. J. Climate, 20, 4819-4834, doi:10.1175/JCLI4282.1.

— A. H. Sobel, A. G. Barnston, and P. Klotzbach, 2010: The influence of natural climate variability, and seasonal forecasts of tropical cyclone activity. Global Perspectives on Tropical Cyclones, from Science to Mitigation, World Scientific Series on Asia-Pacific Weather and Climate, Vol. 4, World Scientific, 325-360.

Cao, X., T. Li, M. Peng, W. Chen, and G. Chen, 2014: Effects of monsoon trough interannual variation on tropical cyclogenesis over the western North Pacific. Geophys. Res. Lett., 41, 4332-4339, doi:10.1002/2014GL060307.

Caron, L.-P., M. Boudreault, and C. L. Bruyère, 2015: Changes in large-scale controls of Atlantic tropical cyclone activity with the phases of the Atlantic multidecadal oscillation. Climate Dyn., 44, 1801-1821, doi:10.1007/s00382-014-2186-5.

Chan, J. C. L., 1985: Tropical cyclone activity in the northwest Pacific in relation to the El Niño/Southern Oscillation phenomenon. Mon. Wea. Rev., 113, 599-606, doi:10.1175/ 1520-0493(1985)113<0599:TCAITN > 2.0.CO;2. 
_ 2000: Tropical cyclone activity over the western North Pacific associated with El Niño and La Niña events. J. Climate, 13, 2960-2972, doi:10.1175/1520-0442(2000)013<2960: TCAOTW $>2.0 . \mathrm{CO} ; 2$

— , and K. S. Liu, 2004: Global warming and western North Pacific typhoon activity from an observational perspective. J. Climate, 17, 4590-4602, doi:10.1175/3240.1.

Chen, T. C., S.-P. Weng, N. Yamazaki, and S. Kiehne, 1998: Interannual variation in the tropical cyclone formation over the western North Pacific. Mon. Wea. Rev., 126, 1080-1090, doi:10.1175/1520-0493(1998)126<1080:IVITTC > 2.0.CO;2.

— S. Y. Wang, and M. C. Yen, 2006: Interannual variation of the tropical cyclone activity over the western North Pacific. J. Climate, 19, 5709-5720, doi:10.1175/JCLI3934.1.

Chia, H. H., and C. F. Ropelewski, 2002: Interannual variability in genesis location of tropical cyclones in the northwest Pacific. J. Climate, 15, 2934-2944, doi:10.1175/1520-0442(2002)015<2934: TIVITG $>2.0 . \mathrm{CO} ; 2$.

Chu, P. S., and X. Zhao, 2007: A Bayesian regression approach for predicting seasonal tropical cyclone activity over the central North Pacific. J. Climate, 20, 4002-4013, doi:10.1175/JCLI4214.1.

Collins, J. M., and I. M. Mason, 2000: Local environment conditions related to seasonal tropical cyclone activity in the northeast Pacific basin. Geophys. Res. Lett., 27, 3881-3884, doi:10.1029/2000GL011614.

Dare, R. A., and J. L. McBride, 2011: The threshold sea surface temperature condition for tropical cyclogenesis. J. Climate, 24, 4570-4576, doi:10.1175/JCLI-D-10-05006.1.

Dee, D. P., and Coauthors, 2011: The ERA-Interim reanalysis: Configuration and performance of the data assimilation system. Quart. J. Roy. Meteor. Soc., 137, 553-597, doi:10.1002/qj.828.

Dowdy, A. J., L. Qi, D. Jones, H. Ramsay, R. Fawcett, and Y. Kuleshov, 2012: Tropical cyclone climatology of the South Pacific Ocean and its relationship to El Niño-Southern Oscillation. J. Climate, 25, 6108-6122, doi:10.1175/JCLI-D-11-00647.1.

Emanuel, K., 1988: The maximum intensity of hurricanes. J. Atmos. Sci., 45, 1143-1155, doi:10.1175/1520-0469(1988)045<1143: $\mathrm{TMIOH}>2.0 . \mathrm{CO} ; 2$.

- 2010: Tropical cyclone activity downscaled from NOAACIRES reanalysis. J. Adv. Model. Earth Syst., 2, 1, 1908-1958, doi:10.3894/JAMES.2010.2.1.

— , and D. S. Nolan, 2004: Tropical cyclone activity and the global climate system. Extended Abstracts, 26th Conf. on Hurricanes and Tropical Meteorology, Miami, FL, Amer. Meteor. Soc., 240-241.

Feng, T., G.-H. Chen, R.-H. Huang, and X.-Y. Shen, 2014: Largescale circulation patterns favorable to tropical cyclogenesis over the western North Pacific and associated barotropic energy conversions. Int. J. Climatol., 34, 216-227, doi:10.1002/ joc.3680.

Frank, W. M., 1987: Tropical cyclone formation. A Global View of Tropical Cyclones, R. L. Elsberry, Ed., U.S. Office of Naval Research, 13-52.

— , and G. S. Young, 2007: The interannual variability of tropical cyclones. Mon. Wea. Rev., 135, 3587-3598, doi:10.1175/ MWR3435.1.

Goldenberg, S. B., C. W. Landsea, A. M. Mestas-Nuñez, and W. M. Gray, 2001: The recent increase in Atlantic hurricane activity: Causes and implications. Science, 293, 474-479, doi:10.1126/science.1060040.

Gray, W. M., 1968: Global view of the origin of tropical disturbances and storms. Mon. Wea. Rev., 96, 669-700, doi:10.1175/ 1520-0493(1968)096<0669:GVOTOO>2.0.CO;2.
_ 1979: Hurricanes: Their formation, structure and likely role in the tropical circulation. Meteorology over the Tropical Oceans, D. B. Shaw, Ed., Royal Meteorological Society, 155218.

1984: Atlantic seasonal hurricane frequency. Part I: El Niño and $30 \mathrm{mb}$ quasibiennial oscillation influences. Mon. Wea. Rev., 112, 1649-1668, doi:10.1175/1520-0493(1984)112<1649: ASHFPI $>2.0 . \mathrm{CO} ; 2$.

Gualdi, S., E. Scoccimarro, and A. Navarra, 2007: Changes in tropical cyclone activity due to global warming: Results from a high-resolution coupled general circulation model. J. Climate, 21, 5204-5228, doi:10.1175/2008JCLI1921.1.

Held, I. M., and M. Zhao, 2011: The response of tropical cyclone statistics to an increase in $\mathrm{CO}_{2}$ with fixed sea surface temperatures. J. Climate, 24, 5353-5364, doi:10.1175/JCLI-D-11-00050.1.

Holland, G. J., 1995: Scale interaction in the western Pacific monsoon. Meteor. Atmos. Phys., 56, 57-79, doi:10.1007/BF01022521. , 1997: The maximum potential intensity of tropical cyclones. J. Atmos. Sci., 54, 2519-2541, doi:10.1175/ 1520-0469(1997)054<2519:TMPIOT>2.0.CO;2.

Hsu, P.-C., P.-S. Chu, H. Murakami, and X. Zhao, 2014: An abrupt decrease in the late-season typhoon activity over the western North Pacific. J. Climate, 27, 4296-4312, doi:10.1175/ JCLI-D-13-00417.1.

Huang, B., and Coauthors, 2014: Extended Reconstructed Sea Surface Temperature version 4 (ERSST.v4). Part I: Upgrades and intercomparisons. J. Climate, 28, 911-930, doi:10.1175/ JCLI-D-14-00006.1.

Irwin, R. P., and R. Davis, 1999: The relationship between the Southern Oscillation index and tropical cyclone tracks in the eastern North Pacific. Geophys. Res. Lett., 26, 2251-2254, doi:10.1029/1999GL900533.

Jiang, H., and E. Zipser, 2010: Contribution of tropical cyclones to the global precipitation from eight seasons of TRMM data: Regional, seasonal, and interannual variations. J. Climate, 23, 1526-1543, doi:10.1175/2009JCLI3303.1.

Jury, M., 1993: A preliminary study of climatological associations and characteristics of tropical cyclones in the SW Indian Ocean. Meteor. Atmos. Phys., 51, 101-115, doi:10.1007/BF01080882.

Kim, H.-M., P. J. Webster, and J. A. Curry, 2011: Modulation of North Pacific tropical cyclone activity by three phases of ENSO. J. Climate, 24, 1839-1849, doi:10.1175/2010JCLI3939.1.

Klotzbach, P. J., 2011: The influence of El Niño-Southern Oscillation and the Atlantic multidecadal oscillation on Caribbean tropical cyclone activity. J. Climate, 24, 721-731, doi:10.1175/ 2010JCLI3705.1.

_ 2014: The Madden-Julian oscillation's impacts on worldwide tropical cyclone activity. J. Climate, 27, 2317-2330, doi:10.1175/ JCLI-D-13-00483.1.

— , and W. M. Gray, 2008: Multidecadal variability in North Atlantic tropical cyclone activity. J. Climate, 21, 3929-3935, doi:10.1175/2008JCLI2162.1.

Knapp, K. R., M. C. Kruk, D. H. Levinson, H. J. Diamond, and C. J. Neumann, 2010: The International Best Track Archive for Climate Stewardship (IBTrACS) unifying tropical cyclone data. Bull. Amer. Meteor. Soc., 91, 363-376, doi:10.1175/ 2009BAMS2755.1.

Knutson, T. R., and Coauthors, 2010: Tropical cyclones and climate change. Nat. Geosci., 3, 157-163, doi:10.1038/ngeo779.

Kuleshov, Y., L. Qi, R. Fawcett, and D. Jones, 2008: On tropical cyclone activity in the Southern Hemisphere: Trends and the ENSO connection. Geophys. Res. Lett., 35, L14S08, doi:10.1029/2007GL032983. 
F. Ming, I. Chouaibon, C. Hoareau, and F. Roux, 2009: Tropical cyclone genesis in the Southern Hemisphere and its relationship with the ENSO. Ann. Geophys., 27, 2523-2538, doi:10.5194/angeo-27-2523-2009.

Lander, M. A., 1994: An exploratory analysis of the relationship between tropical storm formation in the western North Pacific and ENSO. Mon. Wea. Rev., 122, 636-651, doi:10.1175/ 1520-0493(1994)122<0636:AEAOTR > 2.0.CO;2.

Landsea, C. W., R. A. Pielke Jr., A. M. Mestas-Nuñez, and J. A. Knaff, 1999: Atlantic basin hurricanes: Indices of climatic changes. Climatic Change, 42, 89-129, doi:10.1023/A:1005416332322.

Lin, I.-I., and J. C. L. Chan, 2015: Recent decrease in typhoon destructive potential and global warming implications. Nat. Commun., 6, 7182, doi:10.1038/ncomms8182.

Liu, K. S., and J. C. L. Chan, 2013: Inactive period of western North Pacific tropical cyclone activity in 1998-2011. J. Climate, 26, 2614-2630, doi:10.1175/JCLI-D-12-00053.1.

Maloney, E. D., and D. L. Hartmann, 2000: Modulation of eastern North Pacific hurricanes by the Madden-Julian oscillation J. Climate, 13, 1451-1460, doi:10.1175/1520-0442(2000)013<1451: MOENPH $>2.0 . \mathrm{CO} ; 2$.

McBride, J. L., and R. Zehr, 1981: Observational analysis of tropical cyclone formation. Part II: Comparison of non-developing versus developing systems. J. Atmos. Sci., 38, 1132-1151, doi:10.1175/1520-0469(1981)038<1132:OAOTCF >2.0.CO;2.

Menkes, C. E., and Coauthors, 2012: Comparison of tropical cyclogenesis indices on seasonal to interannual timescales. Climate Dyn., 38, 301-321, doi:10.1007/s00382-011-1126-x.

Neelin, J. D., and I. M. Held, 1987: Modeling tropical convergence based on the moist static energy budget. Mon. Wea. Rev., 115, 3-12, doi:10.1175/1520-0493(1987)115<0003: MTCBOT $>2.0 . \mathrm{CO} ; 2$.

Nicholls, N., 1984: The Southern Oscillation, sea-surfacetemperature, and interannual fluctuations in Australian tropical cyclone activity. J. Climatol., 4, 661-670, doi:10.1002/ joc. 3370040609 .

_ C. Landsea, and J. Gill, 1998: Recent trends in Australian region tropical cyclone activity. Meteor. Atmos. Phys., 65, 197205, doi:10.1007/BF01030788.

Nolan, D. S., and E. D. Rappin, 2008: Increased sensitivity of tropical cyclogenesis to wind shear in higher SST environments. Geophys. Res. Lett., 35, L14805, doi:10.1029/ 2008 GL034147.

Patricola, C. M., R. Saravanan, and P. Chang, 2014: The impact of the El Niño-Southern Oscillation and Atlantic meridional mode on seasonal Atlantic tropical cyclone activity. J. Climate, 27, 5311-5328, doi:10.1175/JCLI-D-13-00687.1.

Peduzzi, P., and Coauthors, 2012: Global trends in tropical cyclone risk. Nat. Climate Change, 2, 289-294, doi:10.1038/ nclimate1410.

Peng, M. S., B. Fu, T. Li, and D. E. Stevens, 2012: Developing versus nondeveloping disturbances for tropical cyclone formation. Part I: North Atlantic. Mon. Wea. Rev., 140, 10471066, doi:10.1175/2011MWR3617.1.
Ramsay, H. A., S. J. Camargo, and D. Kim, 2012: Cluster analysis of tropical cyclone tracks in the Southern Hemisphere. Climate Dyn., 39, 897-917, doi:10.1007/s00382-011-1225-8.

Ritchie, E. A., and G. J. Holland, 1999: Large-scale patterns associated with tropical cyclogenesis in the western Pacific. Mon. Wea. Rev., 127, 2027-2043, doi:10.1175/1520-0493(1999)127<2027: LSPAWT>2.0.CO;2.

Seager, R., N. Hendenson, and G. A. Vecchi, 2010: Thermodynamic and dynamic mechanisms for large-scale changes in the hydrological cycle in response to global warming. J. Climate, 23, 4651-4668, doi:10.1175/2010JCLI3655.1.

Tang, B. H., and J. D. Neelin, 2004: ENSO influence on Atlantic hurricanes via tropospheric warming. Geophys. Res. Lett., 31, L24204, doi:10.1029/2004GL021072.

Tippett, M., S. Camargo, and A. Sobel, 2011: A Poisson regression index for tropical cyclone genesis and the role of large-scale vorticity in genesis. J. Climate, 24, 2335-2357, doi:10.1175/2010JCLI3811.1.

Vecchi, G. A., and B. J. Soden, 2007: Effect of remote sea surface temperature change on tropical cyclone potential intensity. Nature, 450, 1066-1070, doi:10.1038/nature 06423.

Vimont, D. J., and J. Kossin, 2007: The Atlantic meridional mode and hurricane activity. Geophys. Res. Lett., 34, L07709, doi:10.1029/2007GL029683.

Vincent, E. M., M. Lengaigne, C. E. Menkes, N. C. Jourdain, P. Marchesiello, and G. Madec, 2011: Interannual variability of the South Pacific convergence zone and implications for tropical cyclone genesis. Climate Dyn., 36, 1881-1896, doi:10.1007/s00382-009-0716-3.

Walsh, K. J., and Coauthors, 2016: Tropical cyclones and climate change. Wiley Interdiscip. Rev.: Climate Change, 7, 65-89, doi:10.1002/wcc.371.

Wang, B., and J. C. L. Chan, 2002: How strong ENSO events affect tropical storm activity over the western North Pacific? J. Climate, 15, 1643-1658, doi:10.1175/1520-0442(2002)015<1643: HSEEAT $>2.0 . \mathrm{CO} ; 2$.

, and X. Zhou, 2008: Climate variation and prediction of rapid intensification in tropical cyclones in the western North Pacific. Meteor. Atmos. Phys., 99, 1-16, doi:10.1007/s00703-006-0238-z.

Wang, C., and S. K. Lee, 2009: Co-variability of tropical cyclones in the North Atlantic and the eastern North Pacific. Geophys. Res. Lett., 36, L24702, doi:10.1029/2009GL041469.

Whitney, L. D., and J. S. Hobgood, 1997: The relationship between sea surface temperature and maximum intensities of tropical cyclones in the eastern North Pacific Ocean. J. Climate, 10, 2921-2930, doi:10.1175/1520-0442(1997)010<2921:TRBSST>2.0.CO;2.

Zhang, G., and G. Wang, 2015: Interannual variability of tropical cyclone activity and regional Hadley circulation over the northeastern Pacific. Geophys. Res. Lett., 42, 2473-2481, doi:10.1002/2015GL063318.

Zhao, J., R. Zhan, Y. Wang, and L. Tao, 2016: Intensified interannual relationship between tropical cyclone genesis frequency over the northwest Pacific and the SST gradient between the southwest Pacific and the western Pacific warm pool since the mid1970s. J. Climate, 29, 3811-3830, doi:10.1175/JCLI-D-15-0729.1. 